\title{
Ten years of MIPAS measurements with ESA Level 2 processor V6 - Part 1: Retrieval algorithm and diagnostics of the products
}

\author{
P. Raspollini ${ }^{1}$, B. Carli ${ }^{1}$, M. Carlotti ${ }^{2}$, S. Ceccherini ${ }^{1}$, A. Dehn ${ }^{11}$, B. M. Dinelli ${ }^{3}$, A. Dudhia ${ }^{4}$, J.-M. Flaud ${ }^{5}$, \\ M. López-Puertas ${ }^{7}$, F. Niro ${ }^{6}$, J. J. Remedios ${ }^{8}$, M. Ridolfi ${ }^{2}$, H. Sembhi ${ }^{8}$, L. Sgheri ${ }^{9}$, and T. von Clarmann ${ }^{10}$ \\ ${ }^{1}$ Istituto di Fisica Applicata "N. Carrara" (IFAC) del Consiglio Nazionale delle Ricerche (CNR), Firenze, Italy \\ ${ }^{2}$ University of Bologna, Bologna, Italy \\ ${ }^{3}$ Istituto di Scienza dell'Atmosfera e del Clima (ISAC) del Consiglio Nazionale delle Ricerche (CNR), Bologna, Italy \\ ${ }^{4}$ Atmospheric, Oceanic and Planetary Physics, Clarendon Laboratory, Oxford University, UK \\ ${ }^{5}$ Laboratoire Interuniversitaire des Systèmes Atmosphériques (LISA) CNRS, Univ. Paris 12 et 7, France \\ ${ }^{6}$ SERCO SpA c/o European Space Agency ESA-ESRIN, Frascati, Italy \\ ${ }^{7}$ Instituto de Astrofísica de Andalucía (CSIC), Granada, Spain \\ ${ }^{8}$ Earth Observation Science, Department of Physics and Astronomy, University of Leicester, UK \\ ${ }^{9}$ Istituto per le Applicazioni del Calcolo (IAC) del Consiglio Nazionale delle Ricerche (CNR), Section of Florence, Italy \\ ${ }^{10}$ Karlsruhe Institute of Technology (KIT), Institute for Meteorology and Climate Research (IMK), Karlsruhe, Germany \\ ${ }^{11}$ ESA-ESRIN, Frascati, Italy \\ Correspondence to: P. Raspollini (p.raspollini@ifac.cnr.it)
}

Received: 4 December 2012 - Published in Atmos. Meas. Tech. Discuss.: 15 January 2013

Revised: 15 July 2013 - Accepted: 5 August 2013 - Published: 23 September 2013

\begin{abstract}
The MIPAS (Michelson Interferometer for Passive Atmospheric Sounding) instrument on the Envisat (Environmental satellite) satellite has provided vertical profiles of the atmospheric composition on a global scale for almost ten years. The MIPAS mission is divided in two phases: the full resolution phase, from 2002 to 2004, and the optimized resolution phase, from 2005 to 2012, which is characterized by a finer vertical and horizontal sampling attained through a reduction of the spectral resolution.

While the description and characterization of the products of the ESA processor for the full resolution phase has been already described in previous papers, in this paper we focus on the performances of the latest version of the ESA (European Space Agency) processor, named ML2PP V6 (MIPAS Level 2 Prototype Processor), which has been used for reprocessing the entire mission. The ESA processor had to perform the operational near real time analysis of the observations and its products needed to be available for data assimilation. Therefore, it has been designed for fast, continuous and automated analysis of observations made in quite different atmospheric conditions and for a minimum use of external constraints in order to avoid biases in the products.
\end{abstract}

The dense vertical sampling of the measurements adopted in the second phase of the MIPAS mission resulted in sampling intervals finer than the instantaneous field of view of the instrument. Together with the choice of a retrieval grid aligned with the vertical sampling of the measurements, this made ill-conditioned the retrieval problem of the MIPAS operational processor. This problem has been handled with minimal changes to the original retrieval approach but with significant improvements nonetheless. The LevenbergMarquardt method, already present in the retrieval scheme for its capability to provide fast convergence for nonlinear problems, is now also exploited for the reduction of the ill-conditioning of the inversion. An expression specifically designed for the regularizing Levenberg-Marquardt method has been implemented for the computation of the covariance matrices and averaging kernels of the retrieved products. The regularization of the Levenberg-Marquardt method is controlled by the convergence criteria and is deliberately kept weak. The resulting oscillations of the retrieved profile are a posteriori damped by an innovative selfadapting Tikhonov regularization. The convergence criteria and the weakness of the self-adapting regularization ensure 
that minimum constraints are used and the best vertical resolution obtainable from the measurements is achieved in all atmospheric conditions.

Random and systematic errors, as well as vertical and horizontal resolution are compared in the two phases of the mission for all products, namely: temperature, $\mathrm{H}_{2} \mathrm{O}, \mathrm{O}_{3}, \mathrm{HNO}_{3}$, $\mathrm{CH}_{4}, \mathrm{~N}_{2} \mathrm{O}, \mathrm{NO}_{2}, \mathrm{CFC}-11, \mathrm{CFC}-12, \mathrm{~N}_{2} \mathrm{O}_{5}$ and $\mathrm{ClONO}_{2}$. The use in the two phases of the mission of different optimized sets of spectral intervals ensures that, despite the different spectral resolutions, comparable performances are obtained in the whole MIPAS mission in terms of random and systematic errors, while the vertical resolution and the horizontal resolution are significantly better in the case of the optimized resolution measurements.

\section{Introduction}

The Michelson Interferometer for Passive Atmospheric Sounding (MIPAS) is a limb-viewing Fourier transform spectrometer that sounded the emission of Earth's atmosphere in the spectral range from 685 to $2410 \mathrm{~cm}^{-1}$ on board the ESA (European Space Agency) Envisat (Environmental satellite) satellite (Fischer et al., 2008).

Its unique observation of the atmospheric emission has provided day and night and regularly spaced sampling that exhaustively characterizes the chemical and physical processes occurring in the atmosphere from 6 to $70 \mathrm{~km}$ altitude, for observations made in nominal mode, and up to $170 \mathrm{~km}$ for observations made in special modes. Table 1 summarizes the main characteristics of the MIPAS spectral bands with the indication of the main molecules emitting in each of them. The satellite was launched on 1 March 2002, and in the first two years of operation (from July 2002 to March 2004) MIPAS acquired, nearly continuously, measurements at full spectral resolution (full resolution (FR) measurements, characterized by the spectral sampling of $0.025 \mathrm{~cm}^{-1}$ ). On 26 March 2004 FR measurements were interrupted because of anomalies in the velocity of the interferometer drive unit of MIPAS and the analysis of instrument reliability and performance recommended the use of a shorter interferometric sweep, corresponding to both a lower spectral resolution $\left(0.0625 \mathrm{~cm}^{-1}\right)$ and a shorter measurement time ( $1.8 \mathrm{~s}$ instead of $4.5 \mathrm{~s})$. Test measurements with reduced spectral resolution were successfully performed in August/September 2004 and, accordingly, the reduction in the measurement time was exploited to make more frequent observations both in the vertical (limb) domain and in the horizontal domain (along the orbit).

With these changes, which provide, for the operational data products, an optimized compromise between spectral and spatial resolutions (optimized resolution, OR), MIPAS restarted operations on 9 January 2005 with a duty cycle shorter than $40 \%$. Since then, due to the recovering performance of the drive unit, the duty cycle was progressively increased until 1 December 2007 when a $100 \%$ duty cycle
Table 1. MIPAS spectral bands: spectral range, NESR, most abundant molecules.

\begin{tabular}{|c|c|c|c|c|}
\hline Band & $\begin{array}{l}\text { Spectral } \\
\text { range } \\
{\left[\mathrm{cm}^{-1}\right]}\end{array}$ & $\begin{array}{l}\text { FR NESR } \\
{\left[\mathrm{nW} \mathrm{cm}^{2}\right.} \\
\left.\mathrm{srcm}^{-1}\right]\end{array}$ & $\begin{array}{l}\text { OR NESR } \\
{\left[\mathrm{nW} \mathrm{cm}^{2}\right.} \\
\left.\mathrm{srcm}^{-1}\right]\end{array}$ & $\begin{array}{l}\text { Most abundant } \\
\text { molecules }\end{array}$ \\
\hline A & $685-970$ & $30-40$ & $20-25$ & $\begin{array}{l}\mathrm{CO}_{2}, \mathrm{O}_{3}, \mathrm{H}_{2} \mathrm{O}, \mathrm{HNO}_{3}, \mathrm{NO}_{2}, \\
\mathrm{CFC}-11, \mathrm{CFC}-12, \mathrm{ClONO} 2\end{array}$ \\
\hline $\mathrm{AB}$ & $1020-1170$ & 20 & 13 & $\mathrm{O}_{3}, \mathrm{~N}_{2} \mathrm{O}, \mathrm{CFC}-12$ \\
\hline B & $1215-1500$ & 15 & 9.5 & $\begin{array}{l}\mathrm{N}_{2} \mathrm{O}_{5}, \mathrm{~N}_{2} \mathrm{O}, \mathrm{CH}_{4}, \mathrm{H}_{2} \mathrm{O}, \mathrm{SO}_{2}, \\
\mathrm{HOCl}, \mathrm{ClONO}{ }_{2}\end{array}$ \\
\hline $\mathrm{C}$ & $1570-1750$ & $3-5$ & $2-2.5$ & $\mathrm{H}_{2} \mathrm{O}, \mathrm{HNO}_{3}, \mathrm{NO}_{2}, \mathrm{ClONO}_{2}$ \\
\hline $\mathrm{D}$ & $1820-2410$ & $3-5$ & $2-2.5$ & $\mathrm{CO}_{2}, \mathrm{O}_{3}, \mathrm{NO}, \mathrm{CO}$ \\
\hline
\end{tabular}

was again attained. MIPAS was successfully operated with this full duty cycle until 8 April 2012, when an Envisat anomaly occurred resulting into the loss of communication between ground and satellite and the end of MIPAS observations (ESA, 2012a).

MIPAS was one of the first Envisat instruments to be fully operational after the launch, providing very high quality Level 1 and Level 2 products. The ESA operational near real time analysis provided from the very beginning vertical profiles of temperature and of volume mixing ratio (VMR) of $\mathrm{H}_{2} \mathrm{O}, \mathrm{O}_{3}, \mathrm{HNO}_{3}, \mathrm{CH}_{4}, \mathrm{~N}_{2} \mathrm{O}$ and $\mathrm{NO}_{2}$ from pole to pole, approximately following the orbital track. In parallel, three other main scientific algorithms have been developed to process MIPAS data. These are the Geofit Multi-Target Retrieval (GMTR) (Carlotti et al., 2006; Dinelli et al., 2010), based on the optimal estimation approach (Rodgers, 2000) and performing a two-dimensional analysis of MIPAS measurements, explicitly handling horizontal inhomogeneities; the algorithm obtained by the joint effort of the Institut für Meteorologie und Klimaforschung (IMK) at Forschungszentrum Karlsruhe and the Instituto de Astrofísica de Andalucía (IAA) (von Clarmann et al., 2003b, 2009b), using Tikhonov regularization, capable of handling deviations from local thermodynamic equilibrium (non-LTE) and taking into account a horizontal gradient of temperature along the line of sight; the algorithm MORSE developed at Oxford University (Dudhia, 2008; Moore and Remedios, 2010), based on the optimal estimation approach (Rodgers, 2000) and using the Reference Forward Model (Dudhia, 2005). The four retrieval algorithms differ for some assumptions in the forward model, for the spectral intervals used for the analysis and for the retrieval approach, and a profitable cross-fertilization has occurred among them. Studies have been performed for the FR measurements proving that in general consistent results for the operational species are obtained by the different algorithms (see von Clarmann et al., 2003a; Fischer et al., 2008), while studies on the OR measurements are currently ongoing and will be reported in later publications. Other retrieval schemes, used principally for the retrieval of CFCs from MIPAS measurements, are OPERA (Moore and Remedios, 2008) and JURASSIC (Hoffmann et al., 2008), which use optimal estimation on spectrally integrated radiances. 
This paper is focused on the ESA processor that was used during the Envisat mission for both the near real time analysis, whose requirement is the distribution of the products within three hours from the measurement time, and for the offline analysis, performed on consolidated Level 1 data, that benefits from a posteriori knowledge related to calibration, auxiliary data and precise orbit information. The capacity of operating in near real time made the MIPAS ESA dataset particularly suitable for the use in operational data assimilation systems. Indeed, near real time MIPAS ozone profiles were actively assimilated at the ECMWF (European Centre for Medium-Range Weather Forecasts) from October 2003 until the end of March 2004 (Dethof, 2003), and, after the interruption in 2004, from 8 December 2011 until 8 April 2012. The assimilation of MIPAS ozone data at the ECMWF was proven to substantially improve the quality of the ECMWF ozone analyses (Dragani, 2012; Thépaut et al., 2012), in particular the good vertical resolution of MIPAS in the stratosphere could provide a very useful constraint on the ozone analyses.

The description and characterization of the ESA processor's products of the full resolution phase was already described in Ridolfi et al. (2000) and Raspollini et al. (2006). In this paper we focus on the performances of the latest version of the ESA processor ML2PP (MIPAS Level 2 Prototype Processor) V6, which has been used for reprocessing the entire MIPAS mission, i.e., including both phases. The complete ML2PP V6 database has been released in 2012 (ESA, $2012 \mathrm{~b}$ ), data access is provided via fast registration at https: //earth.esa.int/web/guest/data-access/browse-data-products.

The ML2PP V6 dataset contains the upgrades that were needed after the change of the operating mode in 2005 both in the algorithm, to cope with the finer altitude sampling of the OR measurements, and in the spectral intervals selected for each retrieval, to cope with the reduced spectral resolution. Since the retrieval is performed at the grid of the measured tangent altitudes and this grid is significantly finer, for the OR measurements, than the MIPAS instantaneous field of view (IFOV, $3 \mathrm{~km}$ ) in the upper troposphere and lower stratosphere, the retrieval of the OR measurements resulted in an ill-conditioned problem and required a regularization approach that was not previously needed for the analysis of the FR measurements. Furthermore, in order to minimize the total error in the two phases of the mission, spectral intervals specifically optimized for each of them were used.

Even if the whole MIPAS mission has now been reprocessed with the same algorithm, the different vertical and horizontal samplings and the different spectral intervals used in the two phases of the mission represent a discontinuity in the measurements whose impact on the products has been carefully investigated. This analysis is split in two parts. The first part, covered by this paper, makes an overview of the choices made for the inversion of the OR measurements starting from the retrieval approach designed for the FR measurements. The paper is then focused on the description of the upgraded diagnostics used for the characterization of the Level 2 products and the comparison of the performances in the two phases of the mission in terms of random and systematic errors and spatial resolution. The second part, covered by a companion paper (Raspollini et al., 2013), will study whether the discontinuity in MIPAS measurements in the two phases has an impact on the bias of the products between the two phases of the mission.

\section{Characteristics of the two phases of the MIPAS mission}

In both phases of the mission different measurement modes are used to observe different processes in the atmosphere with either better sampling or better altitude coverage. Corresponding modes in the two phases of the mission are meant to achieve the same scientific objectives but may slightly differ for the altitude coverage and for the altitude grid. The general objectives of the different measurement modes are shortly reviewed.

The nominal mode (NOM) is the basic mode used to study chemistry and transport and to provide a database for climatology, trend analyses and near real time applications. It is designed to cover the upper troposphere, the stratosphere and the lower mesosphere (approximated boundaries 6-70 km).

The upper troposphere-lower stratosphere (UT-LS) measurement mode, called UTLS-1, is tailored to studies of atmospheric processes in the UT-LS region (including the tropical tropopause layer). It provides a trade-off between vertical and horizontal resolution as well as vertical coverage, ensuring a fine vertical and along-track sampling between the upper troposphere and the middle stratosphere.

The middle atmosphere (MA) mode covers most of the stratosphere, the mesosphere and the lower thermosphere (from 18 to $102 \mathrm{~km}$ ). This mode is dedicated to studying linkages between the upper atmosphere and the stratosphere, i.e., the global circulation and transport of $\mathrm{CO}$ and $\mathrm{NO}_{\mathrm{x}}$ from the mesosphere down to the stratosphere in polar winter hemispheres, as well as solar proton events affecting both the upper atmosphere and the stratosphere. This mode is also used to monitor the quality of operational retrievals that neglect deviations from local thermodynamic equilibrium (non-LTE).

The upper atmosphere (UA) mode covers all the mesosphere and the lowest part of the thermosphere and is mainly dedicated to measurements of high-altitude NO and temperature.

Table 2 summarizes the characteristics of the most used modes in the two phases. For FR measurements details are provided only for the NOM mode, which was the most used one in the first phase. For OR measurements details are provided for the NOM, UTLS-1, MA and UA measurement modes. UTLS- 1 mode was the prevalent mode in the years 2005 and 2006. Then, since December 2007, when MIPAS 
Table 2. Characteristics of FR and OR measurements for the most used measurement modes of the two phases of the mission.

\begin{tabular}{|c|c|c|c|c|c|c|c|}
\hline & & FR measurements & (from $\mathrm{J}$ & ine 2002 to $\mathrm{M}$ & rch 2004) & Spectral resolution: & $0.025 \mathrm{~cm}^{-1}$ \\
\hline Measurement mode & Horizontal sampling & No. of scans & & & Vertical & sampling & \\
\hline \multirow[t]{2}{*}{ NOM } & $550 \mathrm{~km}$ & 17 & & $\begin{array}{l}3 \mathrm{~km} \text { step } \\
6-42 \mathrm{~km}\end{array}$ & $\begin{array}{l}5 \mathrm{~km} \text { step } \\
42-52 \mathrm{~km}\end{array}$ & $\begin{array}{l}8 \mathrm{~km} \text { step } \\
52-68 \mathrm{~km}\end{array}$ & \\
\hline & & OR measurements & (from $\mathrm{J}_{\mathrm{c}}$ & nuary 2005 to & April 2012) & Spectral resolution: & $0.0625 \mathrm{~cm}^{-1}$ \\
\hline Measurement mode & Horizontal sampling & No. of scans & & & Vertical & sampling & \\
\hline NOM & $410 \mathrm{~km}$ & 27 & $\begin{array}{c}1.5 \mathrm{~km} \text { step } \\
6-21 \mathrm{~km}\end{array}$ & $\begin{array}{l}2 \mathrm{~km} \text { step } \\
21-31 \mathrm{~km}\end{array}$ & $\begin{array}{l}3 \mathrm{~km} \text { step } \\
31-46 \mathrm{~km}\end{array}$ & $\begin{array}{l}4 \mathrm{~km} \text { step } \\
46-62 \mathrm{~km}\end{array}$ & $\begin{array}{c}4.5 \mathrm{~km} \text { step } \\
62-71 \mathrm{~km}\end{array}$ \\
\hline UTLS-1 & $290 \mathrm{~km}$ & 19 & & $\begin{array}{l}1.5 \mathrm{~km} \mathrm{step} \\
8-21.5 \mathrm{~km}\end{array}$ & $\begin{array}{c}2 \mathrm{~km} \mathrm{step} \\
21.5-27.5 \mathrm{~km}\end{array}$ & $\begin{array}{c}3 \mathrm{~km} \mathrm{step} \\
27.5-33.5 \mathrm{~km}\end{array}$ & $\begin{array}{c}4.5 \mathrm{~km} \text { step } \\
33.5-51.5 \mathrm{~km}\end{array}$ \\
\hline MA mode & $430 \mathrm{~km}$ & 29 & & & $\begin{array}{c}3 \mathrm{~km} \mathrm{step} \\
18-102 \mathrm{~km}\end{array}$ & & \\
\hline UA mode & $375 \mathrm{~km}$ & 35 & & $\begin{array}{c}3 \mathrm{~km} \text { step } \\
42-102 \mathrm{~km}\end{array}$ & & $\begin{array}{c}5 \mathrm{~km} \mathrm{step} \\
102-172 \mathrm{~km}\end{array}$ & \\
\hline
\end{tabular}

returned to the $100 \%$ duty cycle, regular observations were made with a period of 10 days, consisting of 8 days of NOM mode measurements, 1 day of MA mode and 1 day of UA mode.

In OR measurements, NOM and UTLS-1 modes are characterized by a floating-altitude measurement grid. This means that the limb sounding grid is shifted rigidly with the lowest measured altitude $t$ varying with the latitude, $\theta$, according to $t=A+B \cos (2 \theta)-C \cos \left(90^{\circ}-\operatorname{abs}(\theta)\right)$. In this equation $A=12 \mathrm{~km}, B=0$ and $C=7 \mathrm{~km}$ for the NOM mode and $A=8.5 \mathrm{~km}, B=3 \mathrm{~km}$ and $C=0$ for the UTLS- 1 mode. The floating-altitude sampling grid is meant to follow roughly the tropopause height along the orbit with the requirement to collect at least one spectrum within the troposphere while avoiding too many spectra affected by clouds.

For a detailed description of all measurement modes used in the two phases of the mission see also Oelhaf (2008), while for a detailed calendar of MIPAS measurements see Dudhia (2008).

The MIPAS ML2PP V6 dataset covers all described measurement modes, although MA and UA modes are analyzed by the ESA processor only up to $70 \mathrm{~km}$, since above this altitude the impact of non-LTE cannot be neglected and nonLTE effects are not handled in the forward model of the ESA processor. Analysis of MA and UA modes on the full altitude range are performed with the IMK-IAA algorithm (García-Comas et al., 2012; Bermejo-Pantaleon et al., 2011), while the analysis of UTLS-1 mode with IMK processor is described in Chauhan et al. (2009).

\section{Upgrades in the code}

The measurements of the first phase of the MIPAS mission were originally reprocessed by the ESA Instrument Processing Facilities (IPF) V4.1 and V4.2, based on the Optimized
Retrieval Model (ORM) code described in Ridolfi et al. (2000) and in Raspollini et al. (2006). These measurements were also validated with respect to correlative measurements (Ridolfi et al., 2007; Cortesi et al., 2007; Wang et al., 2007; Payan et al., 2009; Wetzel et al., 2007, 2013, all contained in a MIPAS Special Issue, 2006).

The main features of the algorithm originally designed for the analysis of the FR measurements are as follows.

1. Use of microwindows (MWs), i.e., selected spectral intervals containing relevant information on target parameters and minimizing the systematic errors, which arise chiefly from approximations in the forward model and instrument errors (Dudhia et al., 2002; von Clarmann and Echle, 1998).

2. The forward model computes the radiative transfer integral properly taking into account the atmospheric vertical inhomogeneities but assuming homogeneity in the horizontal direction. Atmosphere is assumed to be in LTE and in hydrostatic equilibrium. The characteristics of the instrument (instrument line shape (ILS) and IFOV) are accurately modeled. The impact of unaccounted atmospheric effects (non-LTE, interfering species, etc.) is minimized through the MW selection. Scattering is not included in the radiative transfer integral, and the spectra affected by thicker clouds, identified by the cloud filtering algorithm (Spang et al., 2002, 2004; Raspollini et al., 2006), are not included in the analysis.

3. The altitude grid of the retrieval is identified by the tangent points of the limb measurements. Only for some species, characterized by a low information content, a retrieval grid coarser than the measurement grid is used in order to avoid a too large ill-conditioning. 
4. For each scan, sequential retrieval of the target species is performed (first $\mathrm{H}_{2} \mathrm{O}$, then $\mathrm{O}_{3}, \mathrm{HNO}_{3}, \mathrm{CH}_{4}, \mathrm{~N}_{2} \mathrm{O}$ and $\mathrm{NO}_{2}$ ) after the simultaneous retrieval of the pressure corresponding to the tangent altitudes and the related temperature values ( $\mathrm{pT}$ retrieval).

5. MW-dependent continuum absorption cross-section profiles and MW-dependent, but height-independent offset calibration values are jointly retrieved with either VMR or $\mathrm{pT}$ retrieval.

6. Initial guess of the target species is determined using the profiles retrieved in the previous scan of the orbit appropriately combined with climatological and ECMWF profiles (if available).

7. Assumed profiles of the interfering species are given, whenever available, by the profiles retrieved in the previous retrievals (either the previous scan or the previous retrievals of the same scan) appropriately combined with climatological and ECMWF profiles (if available).

8. Global fit analysis (Carlotti, 1988) is performed, consisting of the simultaneous fit of the whole limb scanning sequence of the spectra acquired at different tangent altitudes.

9. Nonlinear least squares fit is used with the LevenbergMarquardt minimization and regularizing method (Levenberg, 1944; Marquardt, 1963; Hanke, 1997).

In the following sections, the main changes to the retrieval algorithm are described relative to the algorithm for FR measurements reported in Ridolfi et al. (2000) and in Raspollini et al. (2006). These include the adaptations to the Levenberg-Marquardt method, already utilized in the original FR algorithm, to avoid the ill-conditioning of the retrieval approach and an a posteriori self-adapting Tikhonov regularization technique. Diagnostics of the products specifically studied for the regularizing Levenberg-Marquardt method is also included as well as upgrades to the auxiliary data. Finally, new products are described.

\subsection{The regularizing Levenberg-Marquardt method}

The ESA processor, being specifically designed for the near real time analysis of MIPAS measurements, had to be capable of operating in an automatic way for a long period. These requirements, together with the choice of making a minimal use of external constraints in order to avoid biases in the retrieved profiles, guided our design of the retrieval approach.

Let $y$ be the $m$-dimensional vector of observations with error covariance matrix $\mathbf{S}_{y}$ and $\boldsymbol{f}(\boldsymbol{x})$ the forward model, a nonlinear function of the $n$-dimensional atmospheric state vector $\boldsymbol{x}$. Due to nonlinearities, the problem is solved in a context of Newtonian iterations where $\boldsymbol{f}(\boldsymbol{x})$ is linearized:

$\boldsymbol{f}(\boldsymbol{x})=\boldsymbol{f}\left(\boldsymbol{x}_{i}\right)+\mathbf{K}_{i}\left(\boldsymbol{x}-\boldsymbol{x}_{i}\right)$, with $i$ index of iteration and $\mathbf{K}_{i}$ Jacobian matrix $\frac{\partial f}{\partial x}$ calculated at the linearization point $\boldsymbol{x}_{i}$. The least squares solution of the inverse problem minimizes the cost function:

$\chi^{2}=(\boldsymbol{y}-\boldsymbol{f}(\boldsymbol{x}))^{\mathrm{T}} \mathbf{S}_{y}^{-1}(\boldsymbol{y}-\boldsymbol{f}(\boldsymbol{x}))$.

Minimization of $\chi^{2}$ leads to the Gauss-Newton iteration:

$\boldsymbol{x}_{i+1}=\boldsymbol{x}_{i}+\left(\mathbf{K}_{i}^{\mathrm{T}} \mathbf{S}_{y}^{-1} \mathbf{K}_{i}\right)^{-1} \mathbf{K}_{i}^{\mathrm{T}} \mathbf{S}_{y}^{-1}\left(\boldsymbol{y}-\boldsymbol{f}\left(\boldsymbol{x}_{i}\right)\right)$.

In our application we modify Eq. (3) exploiting the Levenberg-Marquardt (Marquardt, 1963; Levenberg, 1944) method:

$\boldsymbol{x}_{i+1}=\boldsymbol{x}_{i}+\left(\mathbf{K}_{i}^{\mathrm{T}} \mathbf{S}_{y}^{-1} \mathbf{K}_{i}+\alpha_{i} \mathbf{D}_{i}\right)^{-1} \mathbf{K}_{i}^{\mathrm{T}} \mathbf{S}_{y}^{-1}\left(\boldsymbol{y}-\boldsymbol{f}\left(\boldsymbol{x}_{i}\right)\right)$,

where $\mathbf{D}_{i}$ is chosen to be a diagonal matrix with elements equal to those in the diagonal of $\mathbf{K}_{i}^{\mathrm{T}} \mathbf{S}_{y}^{-1} \mathbf{K}_{i}$. Considering that the elements of the state vector are not homogeneous, this approach allows us to provide a correction that is scaled with the error of each element.

The parameter $\alpha_{i}$ is adjusted according to a dampingundamping strategy, see e.g., Lampton (2004). The iterations start with a small $\alpha_{0}$. At each iteration, if the new state $\boldsymbol{x}_{i+1}$ provides a reduction of the chi-square $\left(\chi^{2}\left(\boldsymbol{x}_{i+1}\right)<\chi^{2}\left(\boldsymbol{x}_{i}\right)\right)$, then $\boldsymbol{x}_{i+1}$ is accepted and $\alpha_{i+1}$ is selected such that $\alpha_{i+1}<$ $\alpha_{i}$. If the state $\boldsymbol{x}_{i+1}$ provides an increase of the chi-square $\left(\chi^{2}\left(\boldsymbol{x}_{i+1}\right)>\chi^{2}\left(\boldsymbol{x}_{i}\right)\right)$, then $\boldsymbol{x}_{i+1}$ is rejected and the iteration is repeated with a larger value of $\alpha_{i}$. The iteration is performed until a final iteration criterion is fulfilled (see below).

The Levenberg-Marquardt method has two distinct effects. The first effect is the reduction of the correction applied to the state vector at each iteration, while the correction vector itself is rotated from the Gauss-Newton step direction obtained from Eq. (4) with $\alpha_{i}=0$ towards the opposite direction of the gradient of $\chi^{2}(\boldsymbol{x})$, i.e., the steepest descent direction. It follows that, with a large enough $\alpha_{i}$, the $\chi^{2}$ of the iterates monotonically decreases. By reducing the step length, the Levenberg-Marquardt method avoids making a too large correction, taking the solution outside of the linear approximation range.

The second effect, that has been highly exploited for the analysis of the OR measurements due to the increased illconditioning of the retrieval problem, is that the inversion of the possibly ill-conditioned matrix $\mathbf{K}_{i}^{\mathrm{T}} \mathbf{S}_{y}^{-1} \mathbf{K}_{i}$ is avoided and replaced by the inversion of the matrix $\mathbf{K}_{i}^{\mathrm{T}} \mathbf{S}_{y}^{-1} \mathbf{K}_{i}+$ $\alpha_{i} \mathbf{D}_{i}$, which is better conditioned. This is particularly important when the cost function to be minimized has nearly flat valleys or, which is equivalent, there are subsets of the state space where the cost function has a nearly constant minimum value. The regularizing effect of the LevenbergMarquardt method is discussed in Hanke (1997), Engl et al. (2000), Doicu et al. (2004), Pujol (2007), Doicu et al. (2010), Hochbruck and Honig (2010), Jin (2010), and Böckmann et al. (2011). 
The regularizing Levenberg-Marquardt method is, according to Hanke (1997), a semiconvergent method. Since the regularizing effect decreases with the number of iterations, the noise error increases, and the iterates may not converge in the $\boldsymbol{x}$ space.

The final iteration criteria of the Levenberg-Marquardt iterations should be implemented taking into account two conflicting requirements. On one hand we must avoid stopping the iterations too early, with values of $\chi^{2}$ too far from the minimum. On the other hand, the iterations must be stopped before the noise error becomes too large.

In the literature mentioned above, the consistency criterion is favored as a final iteration criterion, i.e., the iteration is stopped as soon as the $\chi^{2}$ is only slightly larger than its expected minimal value of 1 . For MIPAS this criterion cannot be applied because we do not have a reliable expectation value for the minimum of the reduced $\chi^{2}$ as a consequence of the variability of the systematic errors.

Instead, we use dedicated final iteration criteria.

The Level 2 processor originally used for the analysis of the FR measurements terminated the retrieval iterations (see Raspollini et al., 2006) when at least one of the following two conditions was fulfilled.

1. The relative difference between the actual $\chi^{2}$ and its predicted value in the assumption of the linear forward model is smaller than a predefined threshold $t_{1}$.

2. The maximum inter-iteration relative correction to the target profile vector is less than a predefined threshold $t_{2}$.

In ML2PP V6, the final iteration criteria have been further improved in order to better handle the conflicting requirements in the case of the ill-conditioned retrievals encountered with OR observations. In particular, in ML2PP V6 the condition (1) on the relative difference between $\chi^{2}$ and linear $\chi^{2}$, being a necessary, but not sufficient, condition to guarantee that a local minimum has been reached, is checked only if the actual $\chi^{2}$ is less than a predefined threshold $t_{5}$. Furthermore, two other conditions have been added, the fulfillment of one of the four being sufficient to stop the retrieval. The two additional conditions are as follows.

3. The relative inter-iteration change of $\chi^{2}$ is less than a threshold $t_{3}$. This condition is checked only if the actual $\chi^{2}$ is less than the threshold $t_{5}$.

4. The $n$-dimensional state vector $\boldsymbol{x}_{i}$ at the current iteration $(i)$ is compatible with the state vector $\boldsymbol{x}_{i-1}$ at the previous iteration, within a fraction $t_{4}$ of its error bars represented by the covariance matrix $\mathbf{S}_{i}$ (see Eq. 7).

$$
\sqrt{\frac{\left(\boldsymbol{x}_{i}-\boldsymbol{x}_{i-1}\right)^{\mathrm{T}} \mathbf{S}_{i}^{-1}\left(\boldsymbol{x}_{i}-\boldsymbol{x}_{i-1}\right)}{n}}<t_{4}
$$

The two newly added final iteration criteria allow to reduce, on average, the number of iterations by $18 \%$, while the resulting average $\chi^{2}$ does not increase. The average number of iterations for pT retrieval is about 4 , while it is on average about 3-3.5 for the other retrievals with the exception of $\mathrm{NO}_{2}$, for which the number of iterations is generally 1 or 2 .

Both the chosen thresholds and the fact that the iteration is stopped when one of the final iteration criteria is fulfilled ensure that iterations not achieving a significative reduction of the $\chi^{2}$ are avoided. Because of the ill-conditioning, failing to stop the iterations may produce an unwanted increase of the noise error in the solution, and may result in oscillating profiles. On the other hand, slightly oscillating profiles due to ill-conditioning guarantee that a weak constraint has been used and are therefore tolerable, also considering that the adaptive a posteriori regularization will reduce these oscillations (see Sect. 3.3).

\subsection{Diagnostics of the Levenberg-Marquardt solution}

In ill-conditioned retrievals the Levenberg-Marquardt solution depends, to some degree, on both the initial guess of the state vector and the pathway followed by the iterative minimization procedure. The same dependence exists also for the covariance matrix and the averaging kernels (for their definition see Sect. 4.2) of the Levenberg-Marquardt solution.

For a proper calculation of the covariance and averaging kernel matrices of the Levenberg-Marquardt solution, ML2PP V6 uses an algorithm (Ceccherini and Ridolfi, 2010) in which all the retrieval iterations and the LevenbergMarquardt damping are rigorously taken into account. This is particularly important in the retrieval of OR measurements, since, due to the ill-conditioning of the problem, the Levenberg-Marquardt parameter can be significantly different from zero.

To summarize the equations used, let $i$ be the iteration count and $c$ its value at convergence. For $i=0, \ldots, c$, we define the sequence of gain matrices:

$$
\left(\mathbf{T}_{i}\right)_{j k} \equiv \frac{\partial\left(\boldsymbol{x}_{i}\right)_{j}}{\partial \boldsymbol{y}_{k}} .
$$

With this definition, the covariance $\mathbf{S}_{c}$ and the averaging kernel $\mathbf{A}_{c}$ matrices of the Levenberg-Marquardt solution $\boldsymbol{x}_{c}$ are given by

$$
\begin{aligned}
\mathbf{S}_{c} & =\mathbf{T}_{c} \mathbf{S}_{y} \mathbf{T}_{c}^{\mathrm{T}}, \\
\mathbf{A}_{c} & =\mathbf{T}_{c} \mathbf{K}_{c} .
\end{aligned}
$$

Matrices $\mathbf{T}_{i}$ can be obtained by deriving the LevenbergMarquardt iterative formula (Eq. 4). Considering that the initial guess $\boldsymbol{x}_{0}$ does not depend on the observations $\boldsymbol{y}$, we obtain the following recursive expression: 


$$
\left\{\begin{aligned}
\mathbf{T}_{0}=\mathbf{0} & \\
\mathbf{T}_{i+1} & =\left(\mathbf{K}_{i}{ }^{\mathrm{T}} \mathbf{S}_{y}^{-1} \mathbf{K}_{i}+\alpha_{i} \mathbf{D}_{i}\right)^{-1} \mathbf{K}_{i}^{\mathrm{T}} \mathbf{S}_{y}^{-1}+ \\
& +\left(\mathbf{I}-\left(\mathbf{K}_{i}^{\mathrm{T}} \mathbf{S}_{y}^{-1} \mathbf{K}_{i}+\alpha_{i} \mathbf{D}_{i}\right)^{-1} \mathbf{K}_{i}^{\mathrm{T}} \mathbf{S}_{y}^{-1} \mathbf{K}_{i}\right) \mathbf{T}_{i} .
\end{aligned}\right.
$$

It can be easily shown that in well-conditioned retrievals reaching the exact numerical convergence the covariance and the averaging kernel matrices calculated with Eqs. (7), (8) and (9) coincide with those calculated assuming the last iteration as a Gauss-Newton iteration $\left(\alpha_{c}=0\right)$. On the other hand, in ill-conditioned retrievals and/or in retrievals stopped with a physically meaningful final iteration criterion, the Levenberg-Marquardt solution and its diagnostic tools deviate from those predicted by the Gauss-Newton formulas. Additional tests and discussions on this algorithm can be found in Ceccherini and Ridolfi (2010). The use of this procedure ensures that in ML2PP V6 both covariance and averaging kernel matrices are properly computed even when the Levenberg-Marquardt procedure terminates with a Levenberg-Marquardt parameter significantly different from zero.

\subsection{A posteriori regularization}

As noted in Sect. 3.1, the profiles retrieved using only the Levenberg-Marquardt regularization often exhibit unphysical oscillations. In the Level 2 ESA processor ML2PP V6 these oscillations are damped with a Tikhonov (Tikhonov, 1963) regularization scheme applied, a posteriori, to the Levenberg-Marquardt solution. The expression for the a posteriori regularized solution is

$\boldsymbol{x}=\left(\mathbf{S}_{c}^{-1}+\lambda \mathbf{R}\right)^{-1}\left(\mathbf{S}_{c}^{-1} \boldsymbol{x}_{c}+\lambda \mathbf{R} \boldsymbol{x}_{\mathrm{a}}\right)$.

The regularization matrix $\mathbf{R}$ is obtained using the first derivative operator, and $\boldsymbol{x}_{\mathrm{a}}$ is an a priori profile, which, in our case, is the null vector. This type of regularization is also used by the MIPAS IMK scientific processor (von Clarmann et al., 2003b, 2009b), but contrary to their approach, where the regularization is performed during the iterations and the same regularization strength $\lambda$ is used for all profiles, the ESA processor performs the a posteriori regularization and determines, for each profile, the optimal regularization strength $\lambda$ on the basis of the so-called error consistency method, first introduced in Ceccherini (2005). This method selects the scalar $\lambda$ on the basis of the requirement that the regularized and un-regularized profiles should be compatible within the random error of the regularized profile, adapting its strength on the basis of the measurement error. This criterion leads to an analytical formula for the calculation of the regularization parameter $\lambda$ :

$\lambda=\sqrt{\frac{n}{\left(\boldsymbol{x}_{\mathrm{a}}-\boldsymbol{x}_{c}\right)^{\mathrm{T}} \mathbf{R S}_{c} \mathbf{R}\left(\boldsymbol{x}_{\mathrm{a}}-\boldsymbol{x}_{c}\right)}}$,

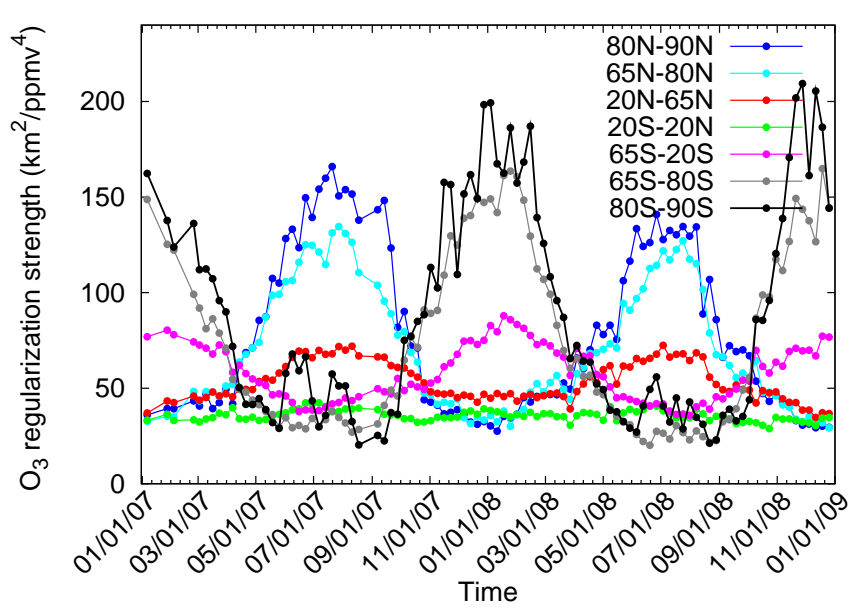

Fig. 1. Time evolution of the regularization strength used in ozone retrieval from January 2007 to December 2008 for the different latitude bands indicated in the plot's key. Points represent weekly means.

where $\mathbf{S}_{c}$ is the covariance matrix of the profile retrieved with the regularizing Levenberg-Marquardt method (Eq. 7).

As shown in Ceccherini (2005) and in Ceccherini et al. (2007a), this regularization parameter provides a significant but rather weak regularization. The existence of an analytical expression makes the error consistency method particularly suitable for implementation in operational retrievals, where the regularization is applied, without direct user supervision, to large sets of profiles with variable noise errors. Figure 1 represents the time evolution of the regularization strength for the ozone retrieval from January 2007 to December 2008 for different latitude bands. The regularization strength presents significant latitudinal and seasonal behavior, that, according to Eq. (11), is anti-correlated with the retrieval error of the profile obtained with the regularizing Levenberg-Marquardt method.

The possibility of adapting the regularization strength to each observation according to its random error makes the bias introduced by the regularization always comparable with the random error. Furthermore, by ensuring that the relative weight of the measurements and the constraint in the cost function to be minimized is maintained approximately constant, the same relative regularization is applied to the profile even when the information content of the measurements changes significantly, with a consequent small variation of the vertical resolution (see Sect. 4.2).

By application of the regularization after a preceding Levenberg-Marquardt retrieval, a completely self-adapting approach is possible that exploits the profile obtained by the regularizing Levenberg-Marquardt method to compute the retrieval error dependent regularization strength. A posteriori regularization was preferred to the use of the regularization within the iterations because the interaction of the two adaptive approaches (Levenberg-Marquardt and regularization 
with error consistency method) makes the retrieval more instable and the convergence slower.

After the a posteriori regularization the covariance and averaging kernel matrices, computed in Eqs. (7) and (8), are updated according to

$\mathbf{S}=\left(\mathbf{S}_{c}^{-1}+\lambda \mathbf{R}\right)^{-1} \mathbf{S}_{c}^{-1}\left(\mathbf{S}_{c}^{-1}+\lambda \mathbf{R}\right)^{-1}$,

$\mathbf{A}=\left(\mathbf{S}_{c}^{-1}+\lambda \mathbf{R}\right)^{-1} \mathbf{S}_{c}^{-1} \mathbf{A}_{c}$.

Since the strength of the regularization is driven by a single scalar parameter $\lambda$ independent of altitude, the error consistency method is not suitable to regularize the water vapor profile for which the VMR and its absolute retrieval error change by two orders of magnitude across the MIPAS retrieval range $(6-70 \mathrm{~km})$. An attempt was made to fix this problem by applying the regularization to the logarithm of the water VMR profile, which is equivalent to considering the relative error instead of the absolute one. However, this approach fails when, because of the retrieval errors, a negative value of the water vapor VMR is retrieved. The constraining of the negative retrieved values to $10^{-10}$ parts per million per volume (ppmv), as described in Sect. 3.6.1, did not help, because for this small value the approximation of the linear error propagation from the profile to the logarithm of the profile fails. In ML2PP V6 this problem with water vapor VMR regularization is temporarily avoided by disabling the a posteriori regularization in water vapor retrievals. In future ESA processor releases this problem will be tackled with a more sophisticated, self-adapting and altitude-dependent regularization scheme first proposed in Ridolfi and Sgheri (2009) and subsequently optimized for the near real time retrieval processors in Ridolfi and Sgheri (2011).

\subsection{Upgrades in the auxiliary data}

In addition to the changes in the algorithm, the analysis of the OR measurements required also new auxiliary data. The main change was made in the MW database, i.e., the database of the spectral intervals selected for the retrieval containing the best information on the target species and being less affected by systematic errors. The MW selection is based on the minimization of the total error, including both random and systematic errors (see Sect. 4.1). The change of the spectral resolution modifies the contribution of each of these errors and leads to a different optimized selection of MWs in the two phases of the mission. Furthermore, the MWs for the analysis of the OR measurements were selected using some modified estimation of these errors, according to the improved knowledge on some MIPAS instrument errors as described in Sect. 4.1.

Tables 3, 4 and 5 list the MWs selected for each species for the analysis of FR and OR measurements. The MWs used for the analysis of the FR measurements are the same as described in Raspollini et al. (2006). The spectral intervals analyzed in the OR measurements are 3-4 times, depending on the different species, wider than those of the old operation mode, even if, because of the reduced spectral resolution, the number of measured spectral points is only 1.2-1.6 times greater. Some points of these MWs are masked (i.e., are not used in the retrieval), and the masks are different at different altitudes. In general the two sets of MWs have only a small number of spectral points in common.

The use of two separate sets of MWs, further than the change in the measurement scenario, represents a discontinuity between the two phases of the mission. The impact of this discontinuity on the retrieval performances is investigated in terms of random and systematic error and spatial resolution in the subsequent sections, while the possible presence of bias between the two phases of the mission due to the different systematic errors affecting the two sets of MWs and to the different measurement scenario will be investigated in a subsequent companion paper (Raspollini et al., 2013).

Further changes in the auxiliary data involve the MIPAS dedicated spectroscopic database. ML2PP V6 uses V3.2 of the spectroscopic database. With respect to V3.1 described in Raspollini et al. (2006), V3.2 includes updates in $\mathrm{NH}_{3}, \mathrm{OCS}, \mathrm{NO}, \mathrm{H}_{2} \mathrm{O}_{2}, \mathrm{HNO}_{3}$, as well as updated pressure broadening (and its temperature dependence) of $\mathrm{H}_{2} \mathrm{O}$ at $948.26288 \mathrm{~cm}^{-1}$.

The climatological profile dataset used (IG2 V4.1) is described in Remedios et al. (2007).

\subsection{New products}

Starting with ML2PP V6, four additional target species, namely, CFC-11, $\mathrm{ClONO}_{2}, \mathrm{~N}_{2} \mathrm{O}_{5}$ and CFC-12, have been operationally processed. These species are retrieved sequentially in this order after the retrieval of the original target species. With the addition of these new target species not only more variables of the atmospheric chemistry are determined providing a more comprehensive overview of the overall atmospheric composition, but also a better understanding of the observed spectrum is attained. Indeed, the use of the retrieved profiles of these species, instead of the IG2, as assumed profiles in the retrieval of the other target species, reduces the errors due to the mutual interference of the species.

The analysis of these species performed by the other MIPAS algorithms, for either a part of the mission or the total mission, are reported in Dudhia (2008), Höpfner et al. (2004), Kellmann et al. (2012), and Mengistu Tsidu et al. (2004). CFC species are crucial for ozone depletion in the upper stratosphere and in the polar regions due to the chlorine released by their photolytic decomposition in the stratosphere; furthermore, since CFCs and most of their replacements are strong infrared absorbers, they contribute significantly to the anthropogenic greenhouse effect. Continuous measurements of these long-lived trace gases are useful to validate transport in atmospheric models. The study of the trends of these species during the whole MIPAS mission 

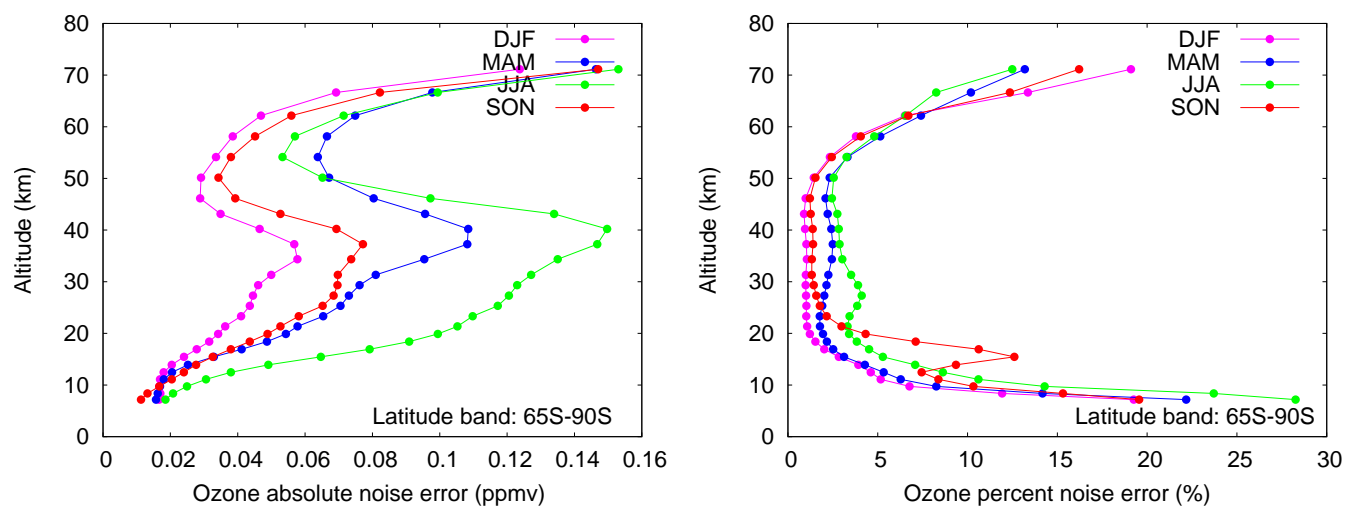

Fig. 2. Absolute (left plot) and percent (right plot) noise error of $\mathrm{O}_{3}$ profile averaged on all profiles of the $65-90^{\circ} \mathrm{S}$ latitude band in the four seasons of year 2008 (December 2007, January and February 2008 (DJF); March, April and May 2008 (MAM); June, July and August 2008 (JJA); September, October and November 2008 (SON)).

Table 3. Spectral intervals selected for the retrieval of pressure and temperature, $\mathrm{H}_{2} \mathrm{O}, \mathrm{O}_{3}$ and $\mathrm{HNO}_{3}$ in the two phases of the mission.

\begin{tabular}{|c|c|c|c|}
\hline & FR & OR & \\
\hline Spectral interval $\left[\mathrm{cm}^{-1}\right]$ & Altitude range $[\mathrm{km}]$ & Spectral interval $\left[\mathrm{cm}^{-1}\right]$ & Altitude range $[\mathrm{km}]$ \\
\hline \multicolumn{4}{|c|}{$\mathrm{pT}$} \\
\hline $685.7-685.825$ & $33-47$ & $703.375-703.875$ & $21-37$ \\
\hline $686.4-689.4$ & $30-68$ & $719.0625-720.625$ & $27-66$ \\
\hline $694.8-695.1$ & $27-36$ & $740.9375-743.9375$ & $15-70$ \\
\hline $700.475-701.1$ & $21-30$ & $791.625-792.25$ & $9-21$ \\
\hline $728.3-729.125$ & $15-27$ & $937.5-940.5$ & $6-23$ \\
\hline $741.975-742.25$ & $15-24$ & $942.31-944.62$ & $6-27$ \\
\hline $791.375-792.875$ & $6-33$ & & \\
\hline \multicolumn{4}{|c|}{$\mathrm{H}_{2} \mathrm{O}$} \\
\hline $807.85-808.45$ & $9-18$ & $953.6875-956.6875$ & $6-40$ \\
\hline $946.65-947.7$ & $6-18$ & $1223.75-1226.25$ & $7.5-18$ \\
\hline $1645.525-1646.2$ & $27-60$ & $1387.5625-1390.5$ & $12-70$ \\
\hline \multirow[t]{2}{*}{$1650.025-1653.025$} & $15-68$ & 1391.75-1394.75 & $12-54$ \\
\hline & & $1649.875-1652.875$ & $15-66$ \\
\hline \multicolumn{4}{|c|}{$\mathrm{O}_{3}$} \\
\hline $763.375-766.375$ & $6-68$ & $729.25-732.25$ & $15-42$ \\
\hline $1039.375-1040.325$ & $52-68$ & $756.625-759.625$ & $9-36$ \\
\hline \multirow[t]{3}{*}{$1122.8-1125.8$} & $6-68$ & $1043-1046$ & $27-68$ \\
\hline & & $1117-1120$ & $6-42$ \\
\hline & & $1123.5625-1126.5625$ & $9-68$ \\
\hline \multicolumn{4}{|c|}{$\mathrm{HNO}_{3}$} \\
\hline $876.375-879.375$ & $6-42$ & $836.875-839.875$ & $6-42$ \\
\hline \multirow[t]{4}{*}{$885.1-888.1$} & $6-42$ & $859.5625-862.5625$ & $9-42$ \\
\hline & & $877.0-880.0$ & $6-42$ \\
\hline & & $893.625-896.625$ & $6-42$ \\
\hline & & $918.9375-921.9375$ & $9-42$ \\
\hline
\end{tabular}


Table 4. Spectral intervals selected for the retrieval of $\mathrm{CH}_{4}, \mathrm{~N}_{2} \mathrm{O}$ and $\mathrm{NO}_{2}$ in the two phases of the mission.

\begin{tabular}{|c|c|c|c|}
\hline & FR & OR & \\
\hline Spectral interval $\left[\mathrm{cm}^{-1}\right]$ & Altitude range $[\mathrm{km}]$ & Spectral interval $\left[\mathrm{cm}^{-1}\right]$ & Altitude range $[\mathrm{km}]$ \\
\hline \multicolumn{4}{|c|}{$\mathrm{CH}_{4}$} \\
\hline $1227.175-1230.175$ & $6-60$ & $1219.0625-1222.0625$ & $9-21$ \\
\hline \multirow[t]{4}{*}{$1350.875-1353.875$} & $12-68$ & $1228.4375-1231.4375$ & $6-60$ \\
\hline & & $1233.8125-1236.8125$ & $6-18$ \\
\hline & & $1281.5625-1284.5625$ & $12-41$ \\
\hline & & $1304.5625-1307.5625$ & $21-18$ \\
\hline \multicolumn{4}{|c|}{$\mathrm{N}_{2} \mathrm{O}$} \\
\hline $1233.275-1236.275$ & $6-27$ & $1230.375-1233.3125$ & $6-21$ \\
\hline \multirow[t]{4}{*}{$1272.05-1275.05$} & $12-60$ & $1233.5625-1235.8125$ & $9-33$ \\
\hline & & $1256.6875-1259.5625$ & $9-30$ \\
\hline & & $1271.625-1274.625$ & $15-60$ \\
\hline & & $1276.3125-1279.3125$ & $15-60$ \\
\hline \multicolumn{4}{|c|}{$\mathrm{NO}_{2}$} \\
\hline $1607.275-1610.275$ & $24-68$ & $1570.5-1573.5$ & $24-27$ \\
\hline $1613.725-1616.6$ & $24-68$ & $1602.5-1605.5$ & $24-60$ \\
\hline \multirow[t]{3}{*}{$1622.55-1623.475$} & $24-30$ & $1608.625-1611.625$ & $24-48$ \\
\hline & & $1613.5-1616.5$ & $24-68$ \\
\hline & & $1626.0-1629.0$ & $24-68$ \\
\hline
\end{tabular}

is important in order to verify the decrease of CFC-11 and CFC-12 in the atmosphere due to the Montreal and successive protocols (Kellmann et al., 2012). Concerning $\mathrm{ClONO}_{2}$ and $\mathrm{N}_{2} \mathrm{O}_{5}$ molecules, they are important reservoir species for nitrogen and chlorine in the stratosphere and play, therefore, an important role in the stratospheric ozone chemistry.

For some of the new species (especially $\mathrm{N}_{2} \mathrm{O}_{5}$ ) the observed features are characterized by broad unresolved bands that are strongly correlated with the fitted atmospheric continuum. Furthermore, the MWs that are used for the retrieval are located in a small spectral region, where the continuum can be assumed approximately constant. In this case, the approach originally used of retrieving a continuum profile for each microwindow has been changed with the possibility of fitting, for selectable species, a single continuum profile common for all the MWs, as also described in Mengistu Tsidu et al. (2004). This new approach is used for the retrieval of $\mathrm{N}_{2} \mathrm{O}_{5}$.

\subsection{Other minor changes and caveats}

For completeness in the following subsections we describe another minor change implemented in ML2PP V6 and a caveat.

\subsubsection{Negative VMRs}

In the previous versions of the ESA Level 2 processor the VMR profiles were constrained to be greater than $10^{-10}$ ppmv after each iteration for all species. This constraint was introduced in order to avoid possible overflow errors in the radiative transfer calculation. However, when the random errors are comparable with the retrieved values of VMR it prevents the occurrence of negative values in the retrieval. This operation is physically justified but it may introduce a positive bias in the statistical distribution of the results. Biases emerged during the comparison of MIPAS FR measurements with correlative measurements, for example for $\mathrm{CH}_{4}$ and $\mathrm{N}_{2} \mathrm{O}$ at high altitudes: from the comparison of a sample of 131 coincident profiles of $\mathrm{CH}_{4}$ in the $70-80^{\circ} \mathrm{N}$ latitude band of MIPAS and ACE-FTS (Atmospheric Chemistry Experiment-Fourier Transform Spectrometer) measurements a positive bias (100. (MIPAS-ACE)/MIPAS) up to $80 \% \pm 8 \%$ was estimated above $60 \mathrm{~km}$ for MIPAS (De Mazière et al., 2008). A similar positive bias is found in MIPAS ESA $\mathrm{N}_{2} \mathrm{O}$ profiles with respect to ACE-FTS (Strong et al., 2008). A method for estimating the bias due to the positive constraint of the profiles is proposed in Funke et al. (2008).

In order to avoid the positive bias in the statistical distribution of the results without reducing the robustness of the code, in ML2PP V6 the constraint to the VMR to be not smaller than $10^{-10} \mathrm{ppmv}$ has been maintained during the iterations but it is now removed at the last iteration. Test comparisons between ML2PP V6 and the previous version of the ESA processor indicate that the elimination of this constraint is successful in reducing the mean value of $\mathrm{CH}_{4}$ above $60 \mathrm{~km}$ and of $\mathrm{N}_{2} \mathrm{O}$ above $50 \mathrm{~km}$ of an amount comparable with the reported positive bias between MIPAS and ACE. 
Table 5. Spectral intervals selected for the retrieval of CFC-11, CFC-12, $\mathrm{N}_{2} \mathrm{O}_{5}$ and $\mathrm{ClONO}_{2}$ in the two phases of the mission.

\begin{tabular}{|c|c|c|c|}
\hline FR & & OR & \\
\hline Spectral interval $\left[\mathrm{cm}^{-1}\right]$ & Altitude range $[\mathrm{km}]$ & Spectral interval $\left[\mathrm{cm}^{-1}\right]$ & Altitude range $[\mathrm{km}]$ \\
\hline \multicolumn{4}{|c|}{ CFC-11 } \\
\hline $839.625-842.625$ & $6-33$ & $824.875-827.0$ & $7.5-21$ \\
\hline $842.65-845.65$ & $6-33$ & $835.0625-838.0625$ & $6-18$ \\
\hline $846.45-849.45$ & $9-33$ & $839.875-842.875$ & $7.5-16.5$ \\
\hline $849.475-852.475$ & $6-33$ & $842.9375-845.9375$ & $6-34$ \\
\hline $853.075-856.075$ & $6-33$ & $849.5-852.5$ & $13.5-34$ \\
\hline \multicolumn{4}{|c|}{ CFC-12 } \\
\hline 918.375-921.375 & $6-39$ & $857.5-860.5$ & $6-40$ \\
\hline $921.4-924.4$ & $6-39$ & $917.9375-920.9375$ & $6-40$ \\
\hline $924.425-927.425$ & $12-39$ & $921.0-924.0$ & $6-40$ \\
\hline $929.125-932.125$ & $6-39$ & $933.625-936.625$ & $6-37$ \\
\hline $1159.7-1162.7$ & $6-39$ & $937.0625-940.0625$ & $12-40$ \\
\hline \multicolumn{4}{|c|}{$\mathrm{ClONO}_{2}$} \\
\hline $778.525-781.525$ & $18-42$ & $777.4375-780.4375$ & $18-37$ \\
\hline $805.4-808.4$ & $18-39$ & $807.375-810.375$ & $15-34$ \\
\hline $808.425-811.425$ & $15-36$ & $1724.0-1727.00$ & $13.5-40$ \\
\hline $1290.625-1293.625$ & $15-42$ & $1736.6875-1739.6875$ & $13.5-43$ \\
\hline 1303.35-1306.35 & $15-42$ & $1743.8125-1746.1875$ & $13.5-31$ \\
\hline \multicolumn{4}{|c|}{$\mathrm{N}_{2} \mathrm{O}_{5}$} \\
\hline $1220.0750-1223.075$ & $15-42$ & $1220.0-1223.0$ & $15-46$ \\
\hline $1272.05-1275.05$ & $15-42$ & $1225.25-1228.25$ & $15-46$ \\
\hline $1225.75-1228.75$ & $15-42$ & $1230.3125-1233.3125$ & $15-40$ \\
\hline $1238.8250-1241.8250$ & $15-42$ & $1237.4375-1240.4375$ & $18-46$ \\
\hline $1243.45-1246.45$ & $15-42$ & $1244.5625-1247.5625$ & $16.5-46$ \\
\hline
\end{tabular}

The need to allow for negative values of the VMRs was identified also for other codes and other species (von Clarmann et al., 2006).

\subsubsection{Altitude bias}

The MIPAS ESA Level 2 processor retrieves the pressure at the tangent levels and the temperature corresponding to this pressure. The spacing between two consecutive tangent altitudes is determined from these quantities using the hydrostatic equilibrium law constrained by the engineering information on the distance between two contiguous tangent altitudes. The location of the altitude grid is determined using the lowest tangent altitude, assumed to be equal to the corresponding engineering value, as a reference point. In this way the tangent altitudes retrieved by the Level 2 processor are affected by a constant bias equal to the error of the engineering measurement at the lowest altitude, which may reach peak values as large as $1.5 \mathrm{~km}$.

No correction of this bias is made in ML2PP V6, but the potential bias in the lowest retrieved tangent altitude has been estimated with a method that takes into account the height and pressure relation provided by the ECMWF atmospheric model high resolution 10 day forecast data (ECMWF, 2009). By minimizing the function given by the sum of the square differences between each of three selected retrieved tangent altitudes (that are function of the lowest engineering tangent altitude) and the corresponding ECMWF value determined by interpolating the ECMWF altitude-pressure grid at the MIPAS pressure levels, the found correction applied to the lowest retrieved tangent altitude (computed on four days of measurements in the four seasons) has a standard deviation of $310 \mathrm{~m}$.

This correction is planned to be included in future versions of the MIPAS ESA processor. Whenever possible the recommendation is to use the tangent pressure as the independent variable to represent retrieved VMR profiles. The use of ECMWF information, although with different mathematics, is made also in the IMK processor (von Clarmann et al., 2003b). 


\section{Characterization of the Level 2 products in the two phases of the mission}

In this section the quality of the products obtained by ML2PP V6 in the two phases of the mission is compared in terms of precision, accuracy and spatial resolution (both vertical and horizontal). It has to be highlighted that, even if the a posteriori regularization is not necessary in the analysis of the FR measurements, it was decided to use it in order to have more consistent products on the whole MIPAS mission, also considering that the a posteriori regularization does not change the convergence point and is completely reversible.

\subsection{Accuracy and precision}

The accuracy of the retrieved profiles is described in terms of the noise error and of the forward model errors.

The noise error is the mapping of the measurement noise in the retrieved profile and its covariance matrix $\mathbf{S}$ is computed using Eq. (12). The covariance matrix of the un-regularized retrieval $\mathbf{S}_{c}$ that appears in Eq. (12) is given by Eq. (7). The covariance matrix of the observations $\mathbf{S}_{y}$ that appears in Eq. (7) is calculated using the radiometric measurement noise (expressed in terms of noise equivalent spectral radiance, NESR) provided by the Level 1 processor, and takes into account the correlation between spectral points due to the apodization process (Raspollini et al., 2006; Ceccherini et al., 2007b). The noise error depends on the sensitivity of the measurements to the target parameters, in turn driven by the temperature profile. Given the large seasonal variability of the temperature profile, especially at latitudes far from the tropics, a large seasonal variability is also observed in the noise error. An example is shown for ozone in Fig. 2, where both the absolute (left plot) and relative (right plot) noise error profiles, averaged in the latitude band $65-90^{\circ} \mathrm{S}$, are reported for the four seasons of 2008. The largest absolute errors are in general observed in the austral winter where the temperatures are coldest. A large relative error is present in the austral spring at the altitudes where ozone depletion occurs, but this is an effect of the significant decrease of ozone rather than a large change in the error.

The forward model errors are given by the propagation in the retrieved profiles of the uncertainties present in the instrument and in the atmospheric model parameters, as well as of the approximations in the forward model itself (Dudhia et al., 2002). All these errors $i$ can be represented as a set of independent error vectors $\delta \mathbf{y}_{i}$ in the measurement space, which are then mapped into corresponding retrieval errors $\delta \mathbf{x}_{i}$ as $\delta \mathbf{x}_{i}=\mathbf{T} \delta \mathbf{y}_{i}$, where $\mathbf{T}$ is the gain matrix (Eq. 6).

The uncertainties in the instrument and the atmospheric model parameters that have been used to estimate the systematic errors of the retrieved profile are the same as used for the FR measurements and have already been reported in Raspollini et al. (2006). The only changes with respect to these values involve the uncertainty in the width of the

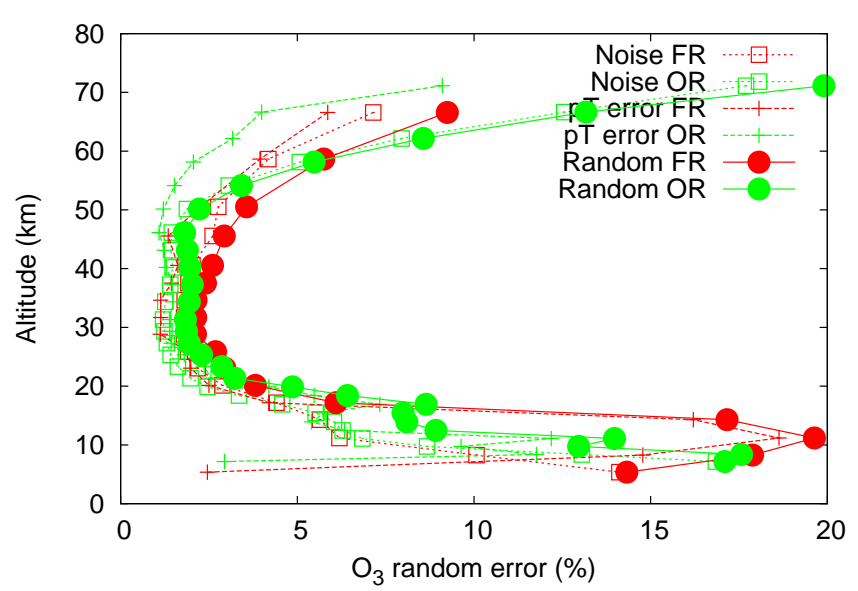

Fig. 3. Contribution of noise error and pressure and temperature propagation error to the random error of $\mathrm{O}_{3}$ for $\mathrm{FR}$ measurements (red curves) and OR measurements (green curves). All errors are in percentage.

apodized instrument line shape, where a value of $0.2 \%$ instead of $2 \%$ has been assumed for the data, and the radiance calibration errors in MIPAS bands C and D (see Table 1), for which the estimated error was changed from 2 to $1 \%$, based on a more accurate estimate of the errors made in the instrument line shape model and in the calibration.

Among the forward model errors, some are random, like the propagation of temperature and pressure noise errors on the VMR profiles (pT propagation error, Raspollini and Ridolfi, 2000), and some are systematic, such as the spectroscopic errors. Others have a value and a variability that may depend on either the time or spatial scale of the profiles that are considered for the statistical analysis.

Here we estimate the single scan random error, for VMR retrievals, by quadratically summing the average single scan noise error and the average single scan error in VMR profiles due to the pT propagation error. The latter is computed by averaging, for a selected set of orbits, the diagonal elements of the covariance matrix of the $\mathrm{pT}$ propagation error relative to each VMR retrieval that is contained in the ESA Level 2 output files.

The contribution to the random error coming from the $\mathrm{pT}$ propagation error profile is generally not negligible with respect to the noise error. Figure 3 provides an example for $\mathrm{O}_{3}$ of the different contributions to the random error for both FR and OR measurements. In this case the contribution to the random error at low altitudes mainly comes from the $\mathrm{pT}$ propagation error, while at high altitudes the noise error and the $\mathrm{pT}$ propagation error contribute in equal manner to the random error. 

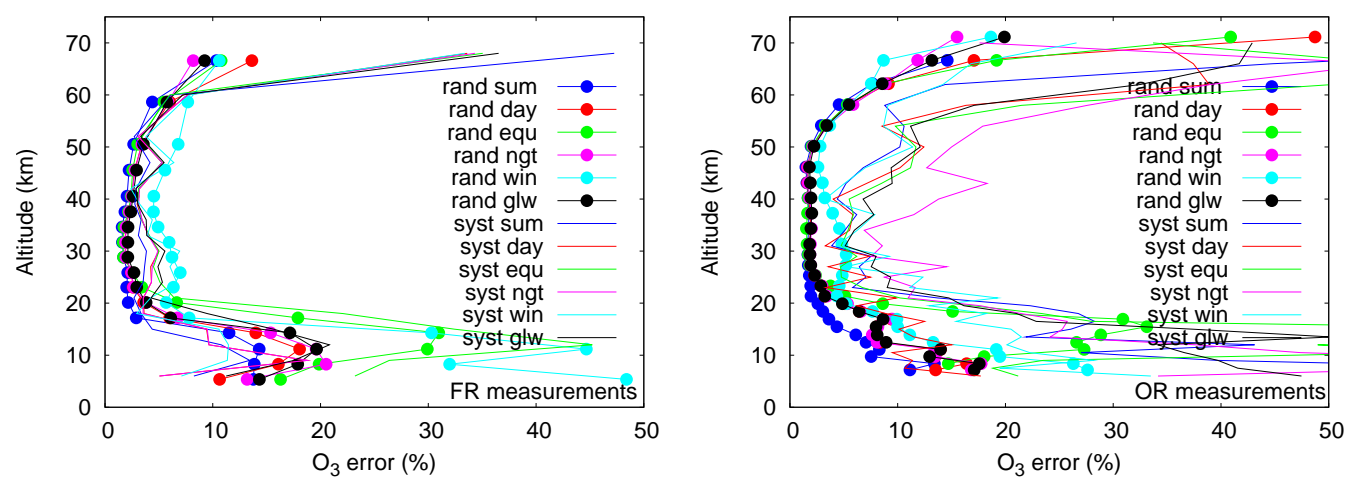

Fig. 4. Percent single scan random and systematic errors of $\mathrm{O}_{3}$ profiles retrieved from $\mathrm{FR}$ (left plot) and OR (right plot) measurements. Both the average random error profiles and the estimated systematic error profiles are provided for the following five reference atmospheres: midlatitude daytime (day), midlatitude nighttime (ngt), polar summer daytime (sum), polar winter nighttime (win) and equatorial daytime atmospheres (equ) (Remedios et al., 2007). Random errors for the global atmosphere (glw) are obtained by averaging the random error profiles of a year of measurements, systematic errors for the global atmosphere are obtained by a composite of results for the five reference atmospheres, with twice the weight given to results from the polar winter case.

The systematic error contribution to the total error budget of the retrieved profiles has been computed as the square root of the quadratic sum of all forward model errors, except for pT propagation error.

Figure 4 shows the percent random and systematic single scan error profiles of the $\mathrm{O}_{3}$ VMR, computed taking into account the contributions described above, for both FR (left plot) and OR (right plot) measurements. Corresponding figures for pressure and temperature, as well as for the VMR of the other species, are reported in the Supplement to the online publication. The random error profiles, obtained by averaging the noise error on either one season or one year of measurements and including the contribution of the pT error propagation error, are shown for five reference atmospheres, i.e., midlatitude daytime (day), midlatitude nighttime (ngt), polar summer daytime (sum), polar winter nighttime (win), equatorial daytime (equ). The estimate of the systematic error profiles is shown for the same reference atmospheres, which are also used for the MW selection (Remedios et al., 2007). Random errors for the global atmosphere (glw) are obtained by averaging the random error profiles of a year of measurements, systematic errors for the global atmosphere are obtained by a composite of results for the five reference atmospheres, with twice the weight given to results from the polar winter case, to ensure that this atmosphere, which is significantly different from the other four, is properly represented. The random error profiles change significantly for different atmospheric conditions, the polar winter atmosphere being characterized by the largest errors. The increase of the random error in polar winter conditions is particularly evident for $\mathrm{CH}_{4}$ (see Fig. 5), since it reaches $40 \%$ for FR measurements and $15 \%$ for OR measurements around $30 \mathrm{~km}$ in South Pole winter conditions, while for the other latitudes and other conditions the random error does not exceed $10 \%$ below $55 \mathrm{~km}$. A similar increase in the random error in polar winter conditions is visible also for other species, especially $\mathrm{H}_{2} \mathrm{O}, \mathrm{N}_{2} \mathrm{O}, \mathrm{NO}_{2}$ and $\mathrm{CFC}-12$ (not shown here, but reported in the supplementary material to the online publication).

Also the systematic errors show a dependence on the atmospheric conditions.

Figures 6 and 7 show, for FR and OR measurements respectively, the global yearly mean of the percent single scan random error profile for all analyzed species (top panels) and the corresponding single scan systematic error profile of the global atmosphere (bottom panels). The random error varies between 5 and $20 \%$, apart, for some species, near the boundaries of the corresponding retrieval range. Similar random errors are obtained for all species in the two phases of the mission, thanks to the selection of a larger number of spectral points in the retrievals from OR measurements.

Also the systematic errors vary between 5 and $20 \%$, although for some species larger errors are obtained near the boundaries of the retrieval range. The systematic errors of FR and OR measurements are on the whole comparable, even though slightly larger errors are usually obtained for OR measurements.

We should also mention that, because we now apply a regularization, the random errors of the FR measurements reported here are smaller than those obtained in the previous processing (see Raspollini et al., 2006). Accordingly, the vertical resolution of FR measurements is here degraded.

\subsection{Vertical resolution}

Further than the covariance matrix, the averaging kernel matrix, which is the retrieval response to variations of the atmospheric status, is needed to characterize the retrieved profile. ML2PP V6 computes the averaging kernel matrix for each retrieved profile, and this is contained in the Level 2 output files. Figure 8 shows all the rows of the ozone averaging 

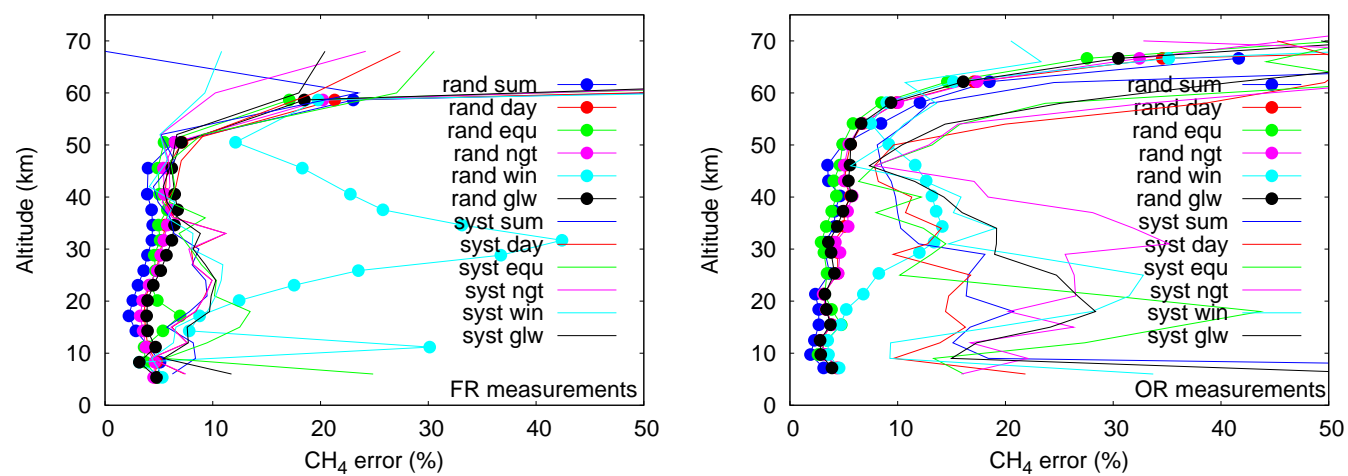

Fig. 5. Same as Fig. 4, but for $\mathrm{CH}_{4}$ profile.
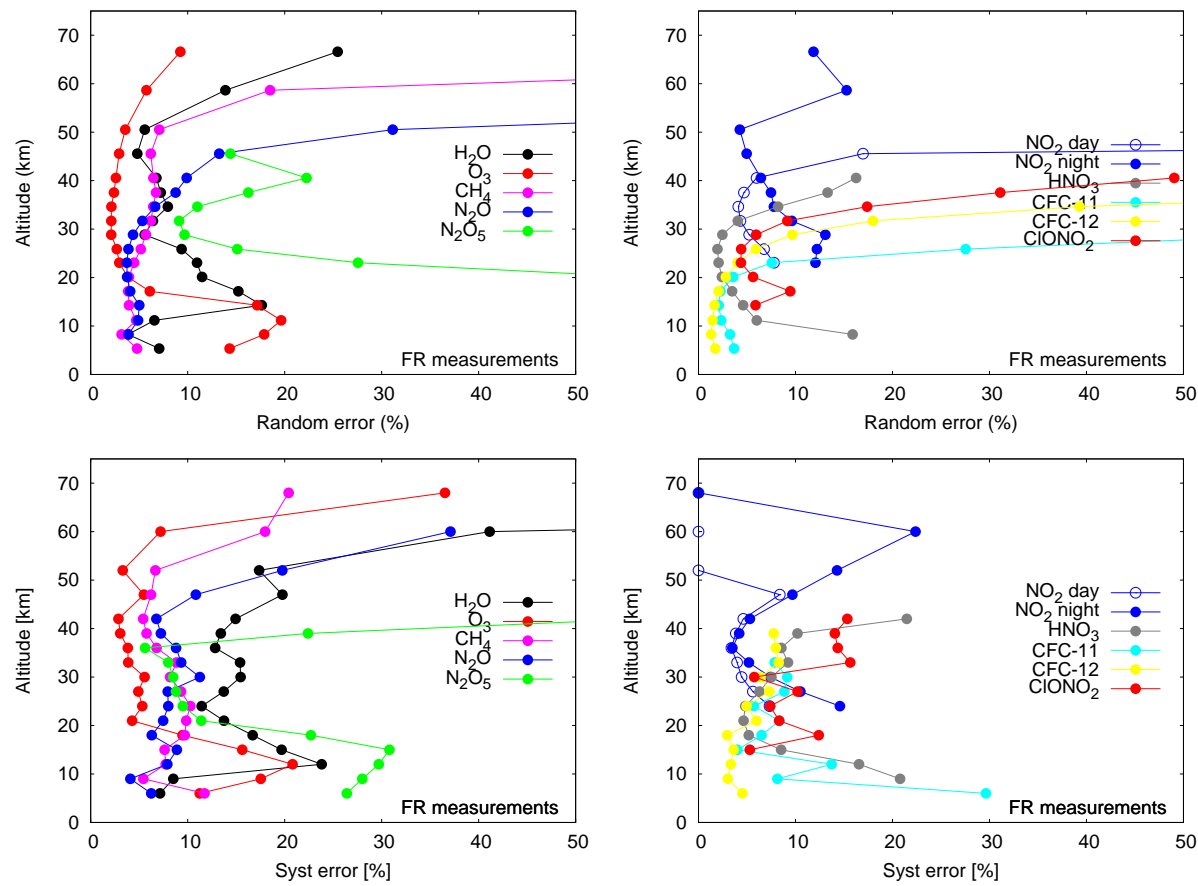

Fig. 6. Top panels: percent yearly mean of single scan random error profiles retrieved from FR measurements for the species indicated in the plots' keys. Bottom panels: corresponding percent single scan systematic error profiles relative to the global atmosphere.

kernel matrix for two representative scans from FR measurements and OR measurements respectively. In the figures, the number of degrees of freedom for the considered scan are also indicated, given by the trace of the AK matrix. Typical values for ozone are, in absence of clouds, 15 for FR measurements and 21.5 for OR measurements. Corresponding figures with the averaging kernels of the other species are reported in the supplementary material to the online publication. For altitudes lower than $30 \mathrm{~km}$ the peaks of FR averaging kernels are closer to 1 than those of OR ones, indicating that for OR measurements a larger constraint is applied in this altitude range, as expected considering the different illconditioning of the retrievals. Nevertheless, the vertical resolution of the profile is significantly better in OR measurements in this altitude range. Indeed, the vertical resolution, further than depending on the constraint of the retrieval and on the IFOV size, is driven by the vertical retrieval grid which is taken equal, for most species, to the measurement grid and is, therefore, finer for OR measurement. The vertical resolution has been estimated as the ratio between the area subtended by the averaging kernel and its diagonal value. This quantity, which in the case of an undersampled distribution is also easily calculated, is an approximate estimation of the full width at half maximum (FWHM) of the averaging kernel rows, coinciding with it in case of a triangular form of the averaging kernel.

Figure 9 shows the vertical resolution profile (averaged on one orbit) and retrieval grid step for the $\mathrm{O}_{3}$ profile for two representative orbits of FR (green curves) and OR measurements (red curves). These quantities are to be compared with 

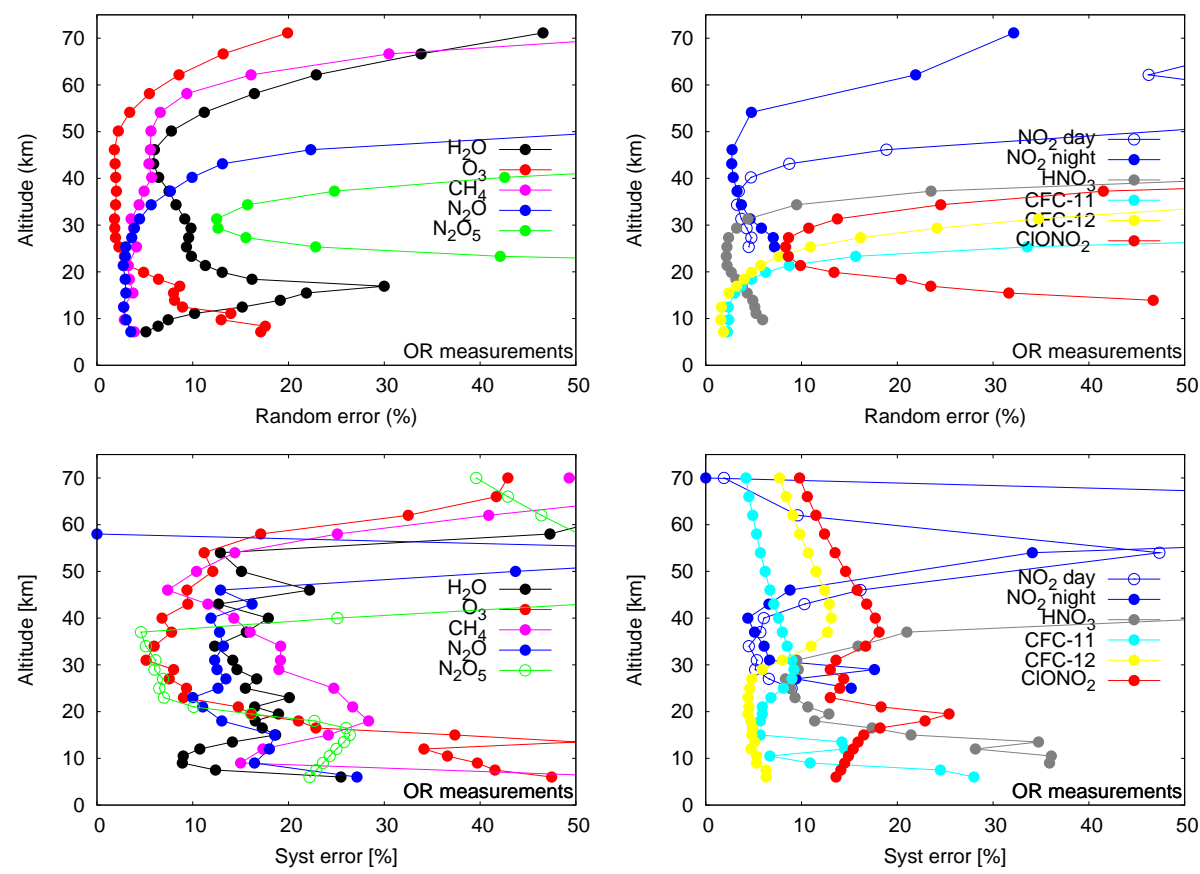

Fig. 7. Top panels: percent yearly mean of single scan random error profiles retrieved from OR measurements for the species indicated in the plots' keys. Bottom panels: corresponding percent single scan systematic error profiles relative to the global atmosphere.

the IFOV of approximately $3 \mathrm{~km}$ measured at tangent altitude point. In the OR measurements the use of a finer measurement grid step allows one to obtain an improved vertical resolution, which in the troposphere and lower stratosphere is often smaller than the IFOV of the instrument. Apart from the change in the vertical resolution due to the change in the measurement scenario, a very small variation of the vertical resolution is found also when a large seasonal variability is observed in the noise error (see Fig. 2). Figure 10 shows the ozone vertical resolution profile, averaged in the latitude band $65-90^{\circ} \mathrm{S}$, for the four seasons of 2008 . The small variation of the vertical resolution for different seasons is a consequence of the self-adapting regularization scheme that is used in the retrieval scheme (see Sect. 3.3).

The same considerations are valid for the profiles of the other species. Figures 11 and 12 show the vertical resolution profiles of the various species respectively for FR and OR measurements. For FR measurements the vertical resolution of all species is between 3 and $5 \mathrm{~km}$ in the altitude range 10 $40 \mathrm{~km}$, and significantly larger above. For OR measurements the vertical resolution varies between 1.5 and $4 \mathrm{~km}$ in the altitude range $10-40 \mathrm{~km}$ for all species except $\mathrm{CH}_{4}, \mathrm{~N}_{2} \mathrm{O}$, CFC12 and CFC-11. For these four species similar performances are obtained in the two phases of the mission because the retrieval of OR measurements is performed on a grid coarser than the measurement grid below $20 \mathrm{~km}$, and hence the retrieval grids are comparable in the two phases of the mission. In particular, the VMR was retrieved on every two points of the measurement grid for $\mathrm{CH}_{4}$ in the altitude range 6-29 km, for $\mathrm{N}_{2} \mathrm{O}$ in the altitude range $6-21 \mathrm{~km}$, for CFC- 11 in the altitude range $6-18 \mathrm{~km}$, for CFC-12 in the altitude range 6$18 \mathrm{~km}$ and also for $\mathrm{NO}_{2}$ in the altitude range 46-71 km.

The water vapor profile is characterized in the two phases of the mission by the best vertical resolution of all the other species, because no regularization is applied (see Sect. 3.3).

\subsection{Horizontal resolution}

The operational retrieval assumes local horizontal homogeneity of the atmosphere, i.e., the vertical profiles are retrieved assuming, at each limb scan, the atmosphere as made of homogeneous spherical shells (Raspollini et al., 2006; Ridolfi et al., 2000).

The state of the real atmosphere, however, changes as a function of the polar coordinate in the limb-scan plane, i.e., the spherical shells used for the discretization of the radiative transfer are not homogeneous. Besides being responsible for an error in the retrieved profiles (Kiefer et al., 2010), this inhomogeneity affects the horizontal resolution of the limb measurements and causes a so-called smoothing error (Rodgers, 2000) in the horizontal domain. This horizontal smoothing must be considered in quantitative applications, e.g., in comparisons of measurements to modeled data and in the data assimilation (e.g., Ide et al., 1997; Lahoz et al., 2007), whenever the model grid is significantly finer than the horizontal resolution of the measurement. Similar considerations apply to the comparison with measurements of different horizontal resolution (e.g., Ridolfi et al., 2007). 

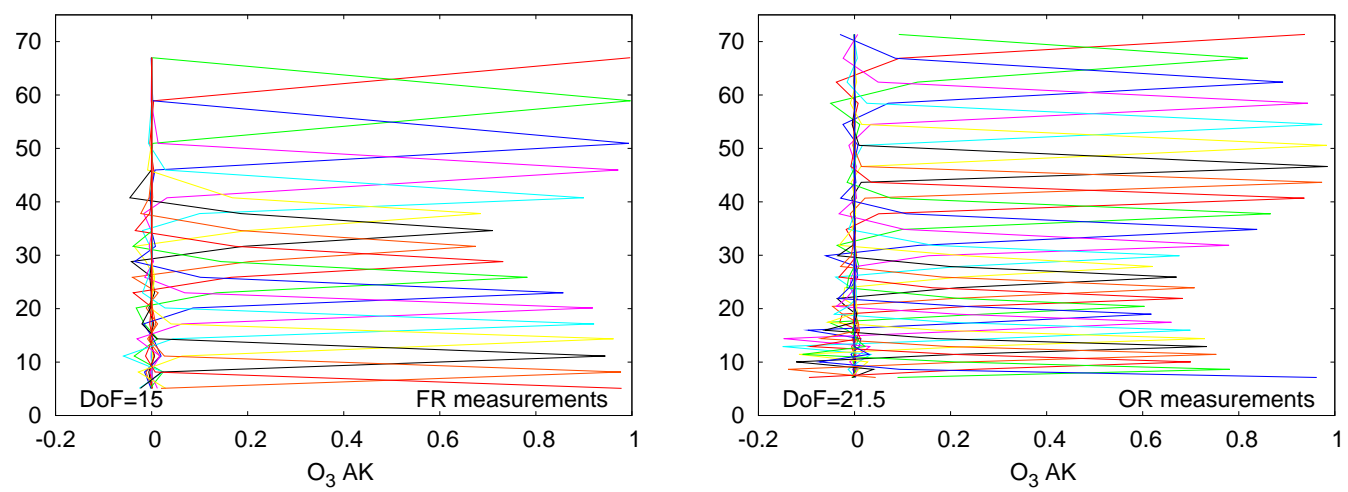

Fig. 8. $\mathrm{O}_{3}$ averaging kernels for two representative scans of FR (left plot) and OR (right plot) measurements.

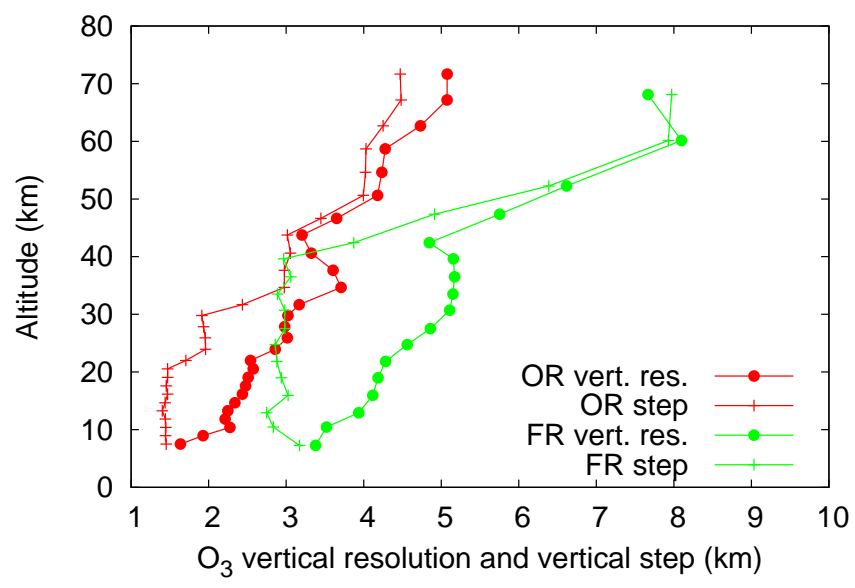

Fig. 9. Vertical resolution profile and vertical retrieval steps for ozone profiles retrieved from FR measurements (green curves) and OR measurements (red curves), as indicated in the plot's key.

A set of horizontal averaging kernels (HAKs), characterizing the horizontal smoothing of MIPAS measurements, has been computed as described in von Clarmann et al. (2009). This set includes HAKs for the MIPAS IG2 atmospheres (Version 4.1, Remedios et al., 2007), i.e., six latitude bands and four seasons for each year and for both FR and OR measurements. The HAKs were calculated assuming the measurement characteristics corresponding to the nominal measurement modes of both the FR and the OR scenarios (see Table 2).

For all the considered cases, the HAKs have a single maximum, therefore it is meaningful to quantify their horizontal spread with the FWHM. We compute this quantity using the same method used for the estimation of the vertical resolution (see Sect. 4.2).

The FWHM of the HAKs shows quite small variations as a function of both latitude and season, therefore here we show only the FWHM relating to a single month (July) and the average over the six latitude bands. Figures 13 (for FR) and 14 (for OR) show the FWHM of HAKs as a function of

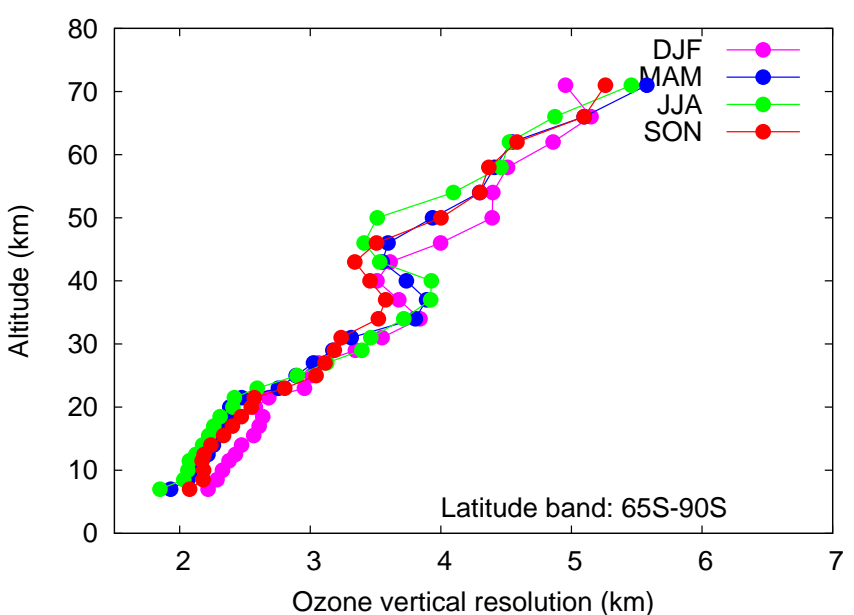

Fig. 10. Ozone vertical resolution profile averaged on all profiles of the $65-90^{\circ} \mathrm{S}$ latitude band in the four seasons of 2008 (DJF, MAM, JJA and SON 2008).

altitude. Each plot contains lines related to temperature and to the VMR of six MIPAS species, as indicated in the plot's key.

In general, below about $40 \mathrm{~km}$ the FWHM of the FR HAKs is between 200 and $300 \mathrm{~km}$ for all MIPAS products; and those corresponding to OR are slightly smaller. Above $40 \mathrm{~km}$, the FR HAKs is between 300 and $600 \mathrm{~km}$, while those of OR are significantly better, still below $300 \mathrm{~km}$ except at the uppermost altitude.

Since the horizontal sampling step of MIPAS limb scans is about $510 \mathrm{~km}$ for FR measurements and about $410 \mathrm{~km}$ for OR measurements (see Table 2), in both cases the atmosphere turns out to be horizontally undersampled at most altitudes. Because of this undersampling, the horizontal resolution of MIPAS measurements in the nominal mode is better quantified by the horizontal sampling (see Table 2) rather than by the FWHM of the HAKs.

Another interesting feature of the MIPAS HAKs is the horizontal shift (or displacement) existing between the 


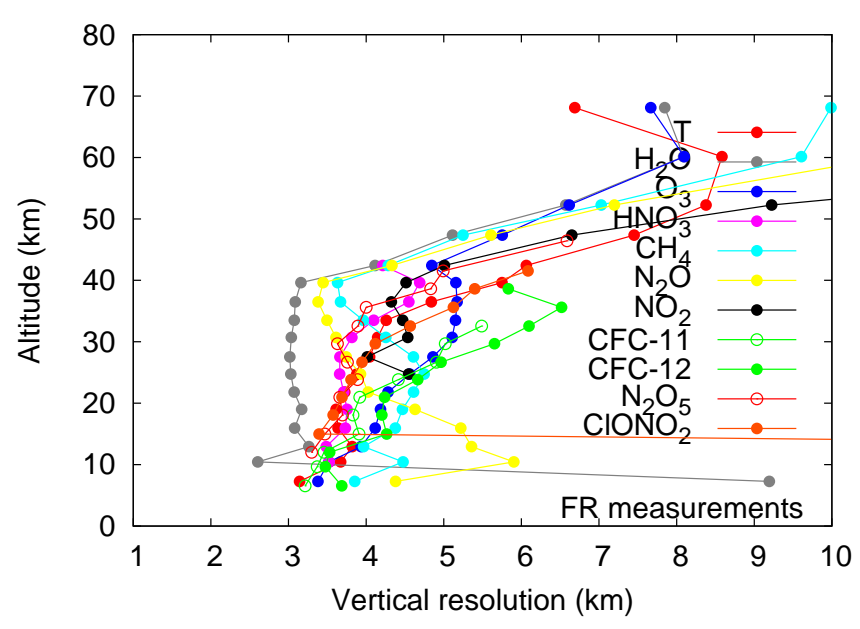

Fig. 11. Vertical resolution profile of $T, \mathrm{H}_{2} \mathrm{O}, \mathrm{O}_{3}, \mathrm{HNO}_{3}, \mathrm{CH}_{4}$, $\mathrm{N}_{2} \mathrm{O}, \mathrm{NO}_{2}, \mathrm{CFC}-12, \mathrm{CFC}-11, \mathrm{ClONO}_{2}$ and $\mathrm{N}_{2} \mathrm{O}_{5}$ retrieved from FR measurements.

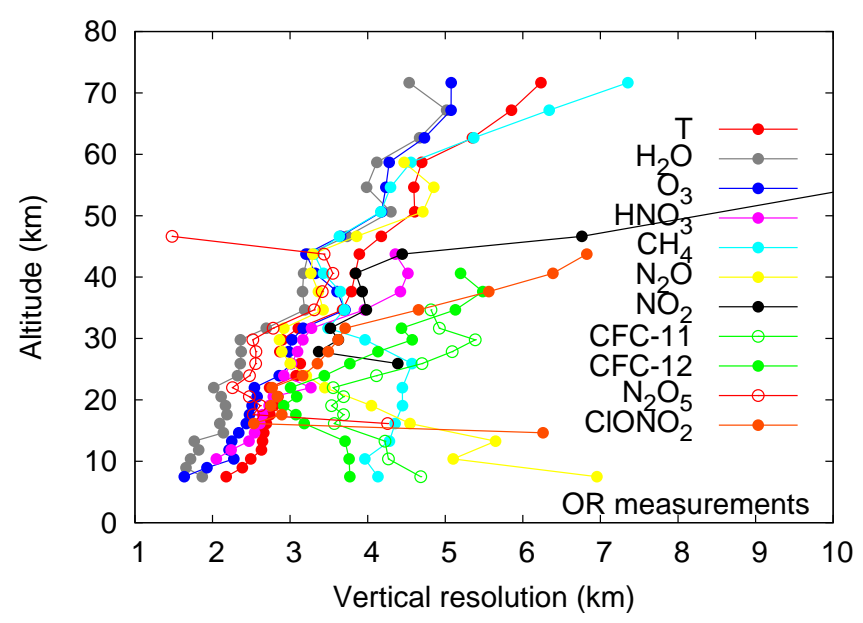

Fig. 12. Vertical resolution profile of $T, \mathrm{H}_{2} \mathrm{O}, \mathrm{O}_{3}, \mathrm{HNO}_{3}, \mathrm{CH}_{4}$, $\mathrm{N}_{2} \mathrm{O}, \mathrm{NO}_{2}, \mathrm{CFC}-12, \mathrm{CFC}-11, \mathrm{ClONO}_{2}$ and $\mathrm{N}_{2} \mathrm{O}_{5}$ retrieved from OR measurements.

geolocation of the tangent point and the point where most of the information comes from. While the retrieved profiles are assumed as geolocated at the tangent points of the limb scan from which they are retrieved, most of the information contributing to the retrieved values comes from air masses shifted towards the satellite with respect to the tangent points. This shift is positively correlated to the opacity of the atmosphere in the spectral region used for the retrieval, and hence it is important in case of large opacity of the MWs used in the retrieval and in presence of significant horizontal variability of the atmosphere. In these conditions the shift may reach, for temperature, the value of $150-200 \mathrm{~km}$. Further details on this shift can be found in von Clarmann et al. (2009a), Carlotti and Magnani (2009), and Carlotti et al. (2013).

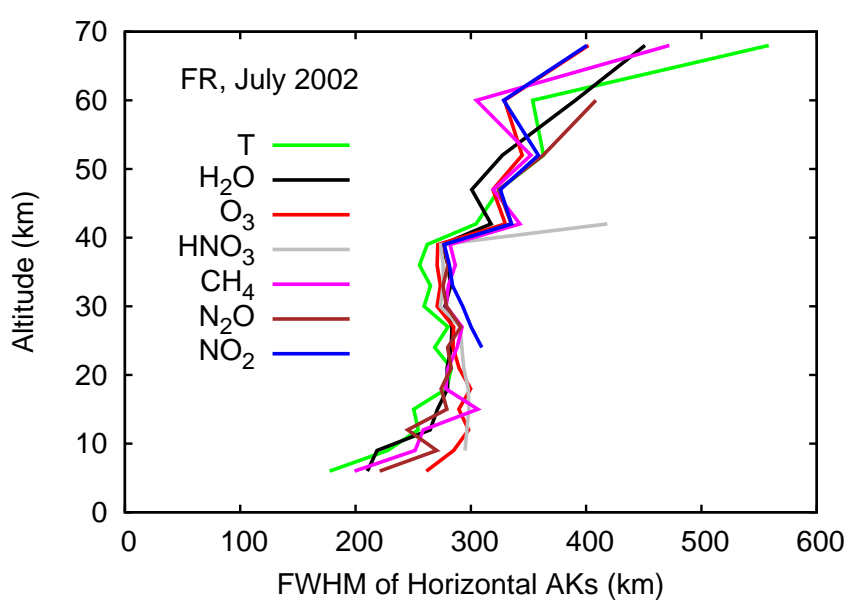

Fig. 13. FWHM of FR horizontal averaging kernels relating to temperature, and the VMR of $\mathrm{H}_{2} \mathrm{O}, \mathrm{O}_{3}, \mathrm{HNO}_{3}, \mathrm{CH}_{4}, \mathrm{~N}_{2} \mathrm{O}, \mathrm{NO}_{2}$. The assumed atmosphere is the one from IG2, July 2002.

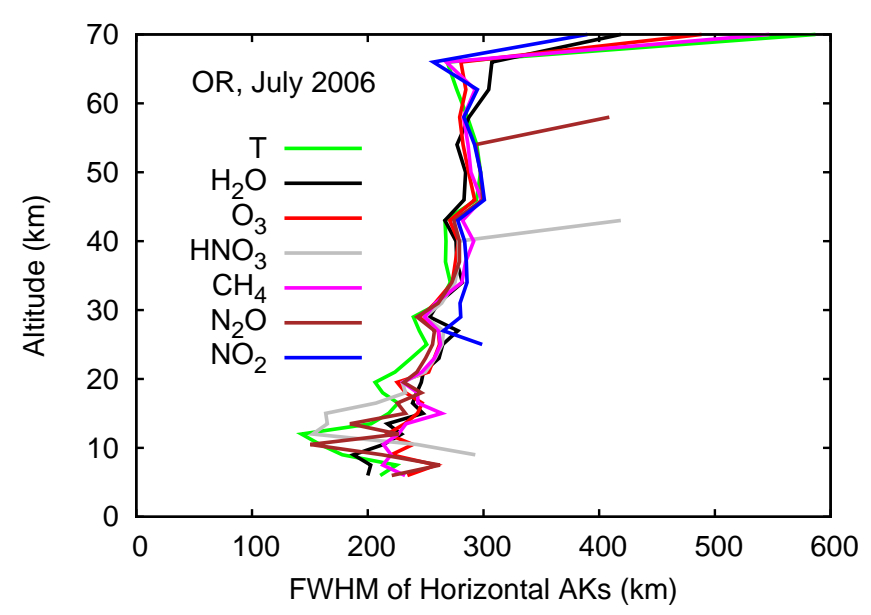

Fig. 14. FWHM of OR horizontal averaging kernels relating to temperature, and the VMR of $\mathrm{H}_{2} \mathrm{O}, \mathrm{O}_{3}, \mathrm{HNO}_{3}, \mathrm{CH}_{4}, \mathrm{~N}_{2} \mathrm{O}, \mathrm{NO}_{2}$. The assumed atmosphere is the one from IG2, July 2006.

\section{Conclusions}

With almost ten years of measurements, MIPAS products constitute an extended and valuable dataset, important for studies of trends, climatology, and in general for the study of the physics and chemistry of the atmosphere. The MIPAS mission is divided in two phases: the so-called FR phase, in the first two years of operation (from July 2002 to March 2004) when the instrument acquired, nearly continuously, measurements at full spectral resolution (sampled at $0.025 \mathrm{~cm}^{-1}$ ); and the so-called OR phase (from January 2005 to April 2012), in which the instrument operated with a reduced spectral resolution $\left(0.0625 \mathrm{~cm}^{-1}\right)$, but improved spatial resolution, that is with more frequent observations both in the vertical (limb) domain and in the horizontal domain (along the orbit). 
The ESA processor has been specifically designed for operating in near real time, and hence for working automatically in different atmospheric conditions, aimed to use the minimum amount of a priori information that may introduce a bias in the profiles.

The algorithm, originally designed for the scenario of the FR measurements, required some modifications for the analysis of the OR measurements, to fully exploit the dense vertical sampling of the OR measurements with a proper handling of the ill-conditioned problem coming from the use of a retrieval grid finer than the IFOV of the instrument.

Looking for self-adapting constraints, the ill-conditioned problem of the OR measurements is handled with the regularizing Levenberg-Marquardt approach during the iterations and an a posteriori regularization with a self-adapting constraint dependent on the random error of each profile. An accurate method specifically designed for the regularizing Levenberg-Marquardt approach is used for the computation of the diagnostic quantities (covariance and averaging kernels). The innovative solutions implemented in ESA processor and discussed in the paper can be useful for the analysis of future limb-sounding missions.

An overview of the performance of the ESA processor ML2PP V6, used for the re-analysis of the entire MIPAS mission, is presented for all the operational species, i.e., $\mathrm{H}_{2} \mathrm{O}, \mathrm{O}_{3}, \mathrm{HNO}_{3}, \mathrm{CH}_{4}, \mathrm{~N}_{2} \mathrm{O}, \mathrm{NO}_{2}, \mathrm{CFC}-11$, CFC-12, $\mathrm{N}_{2} \mathrm{O}_{5}$, $\mathrm{ClONO}_{2}$, further than temperature, and a comparison between the two phases has been carried out. The performed analysis shows that the random and systematic error performances, thanks to the redundant information on the target species present in MIPAS spectra and the consequent use of dedicated MWs in the two phases (larger spectral intervals being used for OR measurements), are generally comparable in the two phases. The single scan random error varies between 5 and $20 \%$ for most species and most altitudes. For the weakest species, near the boundaries of the retrieval range, the percent random error may be significantly larger than these values. The systematic errors are generally larger than the random errors, especially for the OR measurements.

The profiles from OR measurements are characterized by an improved horizontal sampling (about $510 \mathrm{~km}$ for FR measurements, about $410 \mathrm{~km}$ for OR measurements) and an improved vertical resolution (varying, in the altitude range 10$40 \mathrm{~km}$, between 3 and $5 \mathrm{~km}$ for FR measurements, between 1.5 and $4 \mathrm{~km}$ for OR measurements) for most species.

In general, for the species we have analyzed, the OR measurements provide higher quality products than FR measurements.

The random errors, as well as the systematic errors, are dependent on the latitude and season. On the contrary, thanks to the use of a self-adapting regularization schemes in the retrieval algorithm, a small variation of the vertical resolution is obtained for different atmospheric conditions. The minimal use of external constraints, which are prone to introduce biases in the solution, makes ESA processor products suitable for the climatological studies.

The use of different MWs in the two phases and in general the change in the measurement scenario impose some caution when using the full ten year dataset to extract trends. This issue will be further investigated in a subsequent companion paper (Raspollini et al., 2013).

\section{Supplementary material related to this article is available online at http://www.atmos-meas-tech.net/6/ 2419/2013/amt-6-2419-2013-supplement.pdf.}

Acknowledgements. This work has been performed under the ESA study "Support to MIPAS Level 2 product validation", contract ESA-ESRIN no. $21719 / 08 / \mathrm{I}-\mathrm{OL}$. The authors are grateful to the Astrium team that developed the industrial prototype ML2PP using the ORM code as reference, to Thorsten Fehr and Rolf von Kulhmann for the coordination of the MIPAS Quality Working Group activities and to Michael Kiefer for the work done within the MIPAS Quality Working Group.

Edited by: A. Lambert

\section{References}

Bermejo-Pantaleón, D., Funke, B., López-Puertas, M., GarcíaComas, M., Stiller, G. P., von Clarmann, T., Linden, A., Grabowski, U., Höpfner, M., Kiefer, M., Glatthor, N., Kellmann, S., and Lu, G.: Global observations of thermospheric temperature and nitric oxide from MIPAS spectra at $5.3 \mu \mathrm{m}$, J. Geophys. Res., 116, A10313, doi:10.1029/2011JA016752, 2011

Böckmann, C., Kammanee, A., and Braunss, S.: Logarithmic convergence rate of Levenberg-Marquardt method with application to an inverse potential problem, J. Inverse and Ill-Pose. P., 19, 345-367, doi:10.1515/JIIP.2011.034, 2011.

Carlotti, M.: Global-fit approach to the analysis of limb-scanning atmospheric measurements, Appl. Optics, 27, 3250-3254, 1988.

Carlotti, M. and Magnani, L.: Two-dimensional sensitivity analysis of MIPAS observations, Opt. Expr., 17, 5340-5357, 2009.

Carlotti, M., Brizzi, G., Papandrea, E., Prevedelli, M., Ridolfi, M., Dinelli, B. M., and Magnani, L.: GMTR: two-dimensional geofit multitarget retrieval model for Michelson Interferometer for Passive Atmospheric Sounding/environmental satellite observations, Appl. Optics, 45, 716-727, 2006.

Carlotti, M., Arnone, E., Castelli, E., Dinelli, B. M., and Papandrea, E.: Position error in profiles retrieved from MIPAS observations with a 1-D algorithm, Atmos. Meas. Tech., 6, 419-429, doi:10.5194/amt-6-419-2013, 2013.

Ceccherini, S.: Analytical determination of the regularization parameter in the retrieval of atmospheric vertical profiles, Optic. Lett., 30, 2554-2556, 2005.

Ceccherini, S. and Ridolfi, M.: Technical Note: Variance-covariance matrix and averaging kernels for the Levenberg-Marquardt solution of the retrieval of atmospheric vertical profiles, Atmos. Chem. Phys., 10, 3131-3139, doi:10.5194/acp-10-3131-2010, 2010. 
Ceccherini, S., Belotti, C., Carli, B., Raspollini, P., and Ridolfi, M.: Technical Note: Regularization performances with the error consistency method in the case of retrieved atmospheric profiles, Atmos. Chem. Phys., 7, 1435-1440, doi:10.5194/acp-7-1435-2007, 2007a.

Ceccherini, S., Belotti, C., Carli, B., and Raspollini, P.: Use of apodization in quantitative spectroscopy, Opt. Lett., 32, 13291331, 2007b.

Chauhan, S., Höpfner, M., Stiller, G. P., von Clarmann, T., Funke, B., Glatthor, N., Grabowski, U., Linden, A., Kellmann, S., Milz, M., Steck, T., Fischer, H., Froidevaux, L., Lambert, A., Santee, M. L., Schwartz, M., Read, W. G., and Livesey, N. J.: MIPAS reduced spectral resolution UTLS-1 mode measurements of temperature, $\mathrm{O}_{3}, \mathrm{HNO}_{3}, \mathrm{~N}_{2} \mathrm{O}, \mathrm{H}_{2} \mathrm{O}$ and relative humidity over ice: retrievals and comparison to MLS, Atmos. Meas. Tech., 2, 337353, doi:10.5194/amt-2-337-2009, 2009.

Cortesi, U., Lambert, J. C., De Clercq, C., Bianchini, G., Blumenstock, T., Bracher, A., Castelli, E., Catoire, V., Chance, K. V., De Mazière, M., Demoulin, P., Godin-Beekmann, S., Jones, N., Jucks, K., Keim, C., Kerzenmacher, T., Kuellmann, H., Kuttippurath, J., Iarlori, M., Liu, G. Y., Liu, Y., McDermid, I. S., Meijer, Y. J., Mencaraglia, F., Mikuteit, S., Oelhaf, H., Piccolo, C., Pirre, M., Raspollini, P., Ravegnani, F., Reburn, W. J., Redaelli, G., Remedios, J. J., Sembhi, H., Smale, D., Steck, T., Taddei, A., Varotsos, C., Vigouroux, C., Waterfall, A., Wetzel, G., and Wood, S.: Geophysical validation of MIPASENVISAT operational ozone data, Atmos. Chem. Phys., 7, 48074867, doi:10.5194/acp-7-4807-2007, 2007.

De Mazière, M., Vigouroux, C., Bernath, P. F., Baron, P., Blumenstock, T., Boone, C., Brogniez, C., Catoire, V., Coffey, M., Duchatelet, P., Griffith, D., Hannigan, J., Kasai, Y., Kramer, I., Jones, N., Mahieu, E., Manney, G. L., Piccolo, C., Randall, C., Robert, C., Senten, C., Strong, K., Taylor, J., Tétard, C., Walker, K. A., and Wood, S.: Validation of ACE-FTS v2.2 methane profiles from the upper troposphere to the lower mesosphere, Atmos. Chem. Phys., 8, 2421-2435, doi:10.5194/acp-82421-2008, 2008.

Dethof, A.: Assimilation of ozone retrievals from the MIPAS instrument on board ENVISAT, ECMWF technical memorandum No. 428, available at: http://www.ecmwf.int/publications/library/do/ references/list/14 (last access: 13 September 2013), 2003.

Dinelli, B. M., Arnone, E., Brizzi, G., Carlotti, M., Castelli, E., Magnani, L., Papandrea, E., Prevedelli, M., and Ridolfi, M.: The MIPAS2D database of MIPAS/ENVISAT measurements retrieved with a multi-target 2-dimensional tomographic approach, Atmos. Meas. Tech., 3, 355-374, doi:10.5194/amt-3-355-2010, 2010.

Doicu, A., Schreier, F., and Hess, M.: Iterative regularization methods for atmospheric remote sensing, J. Quant. Spectrosc. Ra., 83, 47-61, 2004.

Doicu, A., Trautmann, T., and Schreier, F.: Numerical Regularization for Atmospheric Inverse Problems, Springer, Berlin, 2010.

Dragani, R.: Monitoring and assimilation of SCIAMACHY, GOMOS and MIPAS retrievals at ECMWF. Annual Report for ESA contract 21519/08/I-OL - CCN No. 1: technical support for global validation of ENVISAT data products, 2012.

Dudhia, A.: Reference Forward Model, available at: http://www. atm.ox.ac.uk/RFM (last access: 13 September 2013), 2005.
Dudhia, A.: MIPAS-related section of the web-site of the Oxford University, available at: www.atm.ox.ac.uk/group/mipas (last access: 13 September 2013), 2008.

Dudhia, A., Jay, V. L., and Rodgers, C. D.: Microwindow selection for high-spectral-resolution sounders, Appl. Optics, 41, 36653673, 2002.

ECMWF: Set I: Atmospheric Model high resolution 10-day forecast (HRES), available at: http://www.ecmwf.int/products/catalogue/ I.html (last access: 13 September 2013), 2009.

Engl, H. W., Hanke, M., and Neubauer, A.: Regularization of Inverse Problems, Mathematics and Its Applications, Vol. 44, Kluwer Academic Publishers, The Netherlands, 2000.

ESA: ESA news 9 May 2012: available at: http://www.esa.int/ esaCP/SEM1SXSWT1H_index_0.html (last access: 13 September 2013), 2012a.

ESA: ML2PP V6 dataset: available at: https://earth.esa.int/web/guest/missions/esa-operational-eomissions/envisat/news/-/asset_publisher/x9cY/content/mipaslevel-2-dataset-processed-with-ml2pp-v6-0-is-available-at-dpac (last access: 13 September 2013), 2012b.

Fischer, H., Birk, M., Blom, C., Carli, B., Carlotti, M., von Clarmann, T., Delbouille, L., Dudhia, A., Ehhalt, D., Endemann, M., Flaud, J. M., Gessner, R., Kleinert, A., Koopman, R., Langen, J., López-Puertas, M., Mosner, P., Nett, H., Oelhaf, H., Perron, G., Remedios, J., Ridolfi, M., Stiller, G., and Zander, R.: MIPAS: an instrument for atmospheric and climate research, Atmos. Chem. Phys., 8, 2151-2188, doi:10.5194/acp-8-2151-2008, 2008.

Funke, B., López-Puertas, M., Garcia-Comas, M., Stiller, G. P., von Clarmann, T., and Glatthor, N.: Mesospheric $\mathrm{N}_{2} \mathrm{O}$ enhancements as observed by MIPAS on Envisat during the polar winters in 2002-2004, Atmos. Chem. Phys., 8, 5787-5800, doi:10.5194/acp-8-5787-2008, 2008.

García-Comas, M., Funke, B., López-Puertas, M., BermejoPantaleón, D., Glatthor, N., von Clarmann, T., Stiller, G., Grabowski, U., Boone, C. D., French, W. J. R., Leblanc, T., López-González, M. J., and Schwartz, M. J.: On the quality of MIPAS kinetic temperature in the middle atmosphere, Atmos. Chem. Phys., 12, 6009-6039, doi:10.5194/acp-12-6009-2012, 2012.

Hanke, M.: A regularizing Levenberg-Marquardt scheme, with applications to inverse groundwater filtration problems, Inverse Problems, 13, 79-95, 1997.

Hochbruck, M. and Honig, M.: On the convergence of a regularizing Levenberg-Marquardt scheme for nonlinear ill-posed problems, Numer. Math., 115, 71-79, doi:10.1007/s00211-009-02689, 2010.

Hoffmann, L., Kaufmann, M., Spang, R., Müller, R., Remedios, J. J., Moore, D. P., Volk, C. M., von Clarmann, T., and Riese, M.: Envisat MIPAS measurements of CFC-11: retrieval, validation, and climatology, Atmos. Chem. Phys., 8, 3671-3688, doi:10.5194/acp-8-3671-2008, 2008.

Höpfner, M. von Clarmann, T., Fischer, H., Glatthor N., Grabowski, U., Kellmann, S., Kiefer, M., Linden, A., Mengistu Tsidu, G., Milz, M., Steck, T., Stiller, G. P., Wang, D.-Y., and Funke, B.: First spaceborne observations of antarctic stratospheric $\mathrm{ClONO}_{2}$ recovery: austral spring 2002, J. Geophys. Res., 109, D11308, doi:10.1029/2004JD004609, 2004. 
Ide, K., Courtier, P., Ghil, M., and Lorenc, A. C.: Unified notation for data assimilation: operational, sequential and variational, J. Meteorol. Soc. Jpn., 75, 181-189, 1997.

Jin, Q.: On a regularized Levenberg-Marquardt method for solving nonlinear inverse problems, Numer. Math., 115, 229-259, 2010.

Kellmann, S., von Clarmann, T., Stiller, G. P., Eckert, E., Glatthor, N., Höpfner, M., Kiefer, M., Orphal, J., Funke, B., Grabowski, U., Linden, A., Dutton, G. S., and Elkins, J. W.: Global CFC-11 $\left(\mathrm{CCl}_{3} \mathrm{~F}\right)$ and CFC-12 $\left(\mathrm{CCl}_{2} \mathrm{~F}_{2}\right)$ measurements with the Michelson Interferometer for Passive Atmospheric Sounding (MIPAS): retrieval, climatologies and trends, Atmos. Chem. Phys., 12, 11857-11875, doi:10.5194/acp-12-118572012, 2012.

Kiefer, M., Arnone, E., Dudhia, A., Carlotti, M., Castelli, E., von Clarmann, T., Dinelli, B. M., Kleinert, A., Linden, A., Milz, M., Papandrea, E., and Stiller, G.: Impact of temperature field inhomogeneities on the retrieval of atmospheric species from MIPAS IR limb emission spectra, Atmos. Meas. Tech., 3, 1487-1507, doi:10.5194/amt-3-1487-2010, 2010.

Lahoz, W. A., Errera, Q., Swinbank, R., and Fonteyn, D.: Data assimilation of stratospheric constituents: a review, Atmos. Chem. Phys., 7, 5745-5773, doi:10.5194/acp-7-5745-2007, 2007.

Lampton, M: Damping-undamping strategies for the LevenbergMarquardt nonlinear least-squares method, Comput. Phys., 11, 110-115, 1997.

Levenberg, K.: A method for the solution of certain problems in least squares, Q. Appl. Math., 2, 164-168, 1944.

Marquardt, D. W.: An algorithm for the least-squares estimation of nonlinear parameters, SIAM, J. Appl. Math., 11, 431-441, 1963.

Mengistu Tsidu, G., von Clarmann, T., Stiller, G. P., Höpfner, M., Fischer, H., Glatthor, N., Grabowski, U., Kellmann, S., Kiefer, M., Linden, A., Milz, M., Steck, T., Wang, D. Y., and Funke, B.: Stratospheric $\mathrm{N}_{2} \mathrm{O}_{5}$ in the austral spring 2002 as retrieved from limb emission spectra recorded by the Michelson Interferometer for Passive Atmospheric Sounding (MIPAS), J. Geophys. Res., 109, D18301, doi:10.1029/2004JD004856, 2004.

MIPAS (Michelson Interferometer for Passive Atmosphere Sounding): Potential of the experiment, data processing and validation of results, edited by: Hartogh, P. and Espy, P. J., ACP Special Issues, 2006.

Moore, D. P. and Remedios, J. J.: Growth rates of stratospheric HCFC-22, Atmos. Chem. Phys., 8, 73-82, doi:10.5194/acp-873-2008, 2008.

Moore, D. P. and Remedios, J. J.: Seasonality of Peroxyacetyl nitrate (PAN) in the upper troposphere and lower stratosphere using the MIPAS-E instrument, Atmos. Chem. Phys., 10, 6117-6128, doi:10.5194/acp-10-6117-2010, 2010.

Oelhaf, H.: MIPAS mission plan, ENVI-SPPA-EOPG-TN-07-0073, Version 4.3, 2008.

Pujol, J.: The solution of nonlinear inverse problems and the Levenberg-Marquardt method, Geophysics, 72, W1-W16, 2007.

Payan, S., Camy-Peyret, C., Oelhaf, H., Wetzel, G., Maucher, G., Keim, C., Pirre, M., Huret, N., Engel, A., Volk, M. C., Kuellmann, H., Kuttippurath, J., Cortesi, U., Bianchini, G., Mencaraglia, F., Raspollini, P., Redaelli, G., Vigouroux, C., De Mazière, M., Mikuteit, S., Blumenstock, T., Velazco, V., Notholt, J., Mahieu, E., Duchatelet, P., Smale, D., Wood, S., Jones, N., Piccolo, C., Payne, V., Bracher, A., Glatthor, N., Stiller, G., Grunow, K., Jeseck, P., Te, Y., and Butz, A.: Validation of version-4.61 methane and nitrous oxide observed by MIPAS, Atmos. Chem. Phys., 9, 413-442, doi:10.5194/acp-9-413-2009, 2009.

Raspollini, P. and Ridolfi, M.: Mapping of temperature and line of sight errors in constituent retrievals for MIPAS/ENVISAT measurements, Atmos. Environ., 34, 5329-5336, 2000.

Raspollini, P., Belotti, C., Burgess, A., Carli, B., Carlotti, M., Ceccherini, S., Dinelli, B. M., Dudhia, A., Flaud, J.-M., Funke, B., Höpfner, M., López-Puertas, M., Payne, V., Piccolo, C., Remedios, J. J., Ridolfi, M., and Spang, R.: MIPAS level 2 operational analysis, Atmos. Chem. Phys., 6, 5605-5630, doi:10.5194/acp6-5605-2006, 2006.

Raspollini, P., Carli, B., Carlotti, M., Ceccherini, S., Dinelli, B. M., Dudhia, A., Flaud, J. M., Kiefer, M., Lopez-Puertas, M., Remedios, J., Ridolfi, M., and Sgheri, L.: Ten years of MIPAS measurements with ESA Level 2 operational processor - Part 2: Consistency of the products in the two phases of the mission and their validation, in preparation, 2013.

Remedios, J. J., Leigh, R. J., Waterfall, A. M., Moore, D. P., Sembhi, H., Parkes, I., Greenhough, J., Chipperfield, M. P., and Hauglustaine, D.: MIPAS reference atmospheres and comparisons to V4.61/V4.62 MIPAS level 2 geophysical data sets, Atmos. Chem. Phys. Discuss., 7, 9973-10017, doi:10.5194/acpd-79973-2007, 2007.

Ridolfi, M. and Sgheri, L.: A self-adapting and altitude-dependent regularization method for atmospheric profile retrievals, Atmos. Chem. Phys., 9, 1883-1897, doi:10.5194/acp-9-1883-2009, 2009.

Ridolfi, M. and Sgheri, L.: Iterative approach to self-adapting and altitude-dependent regularization for atmospheric profile retrievals, Opt. Express, 19, 26696-26709, 2011.

Ridolfi, M., Carli, B., Carlotti, M., von Clarmann, T., Dinelli, B. M., Dudhia, A., Flaud, J. M., Höpfner, M., Morris, P. E., Raspollini, P., Stiller, G., and Wells, R. J.: Optimized forward model and retrieval scheme for MIPAS near-real-time data processing, Appl. Optics, 39, 1323-1340, 2000.

Ridolfi, M., Blum, U., Carli, B., Catoire, V., Ceccherini, S., Claude, H., De Clercq, C., Fricke, K. H., Friedl-Vallon, F., Iarlori, M., Keckhut, P., Kerridge, B., Lambert, J.-C., Meijer, Y. J., Mona, L., Oelhaf, H., Pappalardo, G., Pirre, M., Rizi, V., Robert, C., Swart, D., von Clarmann, T., Waterfall, A., and Wetzel, G.: Geophysical validation of temperature retrieved by the ESA processor from MIPAS/ENVISAT atmospheric limbemission measurements, Atmos. Chem. Phys., 7, 4459-4487, doi:10.5194/acp-7-4459-2007, 2007.

Rodgers, C. D.: Inverse Methods for Atmospheric Sounding: Theory and Practice, Atmospheric, Oceanic and Planetary Physics, World Scientific, Singapore, 2000.

Spang, R., Eidmann, G., Riese, M., Preusse, P., Offermann, D., Pfister, L., and Wang, P. H.: CRISTA observations of cirrus clouds around the tropopause, J. Geophys. Res., 107, 8174, doi:10.1029/2001JD000698, 2002.

Spang, R., Remedios, J. J., and Barkley, M.: Colour indices for the detection and differentiation of cloud types in infra-red limb emission spectra, Adv. Space Res., 33, 1041-1047, 2004.

Strong, K., Wolff, M. A., Kerzenmacher, T. E., Walker, K. A., Bernath, P. F., Blumenstock, T., Boone, C., Catoire, V., Coffey, M., De Mazière, M., Demoulin, P., Duchatelet, P., Dupuy, E., Hannigan, J., Höpfner, M., Glatthor, N., Griffith, D. W. T., 
Jin, J. J., Jones, N., Jucks, K., Kuellmann, H., Kuttippurath, J., Lambert, A., Mahieu, E., McConnell, J. C., Mellqvist, J., Mikuteit, S., Murtagh, D. P., Notholt, J., Piccolo, C., Raspollini, P., Ridolfi, M., Robert, C., Schneider, M., Schrems, O., Semeniuk, K., Senten, C., Stiller, G. P., Strandberg, A., Taylor, J., Tétard, C., Toohey, M., Urban, J., Warneke, T., and Wood, S.: Validation of ACE-FTS $\mathrm{N}_{2} \mathrm{O}$ measurements, Atmos. Chem. Phys., 8, 4759-4786, doi:10.5194/acp8-4759-2008, 2008.

Thépaut, J.-N., Dragani, R., Abdalla, S., and Engelen, R.: Assimilation of ENVISAT data for numeric weather prediction, enviromental monitoring and reanalysis applications, Proceedings of IGARSS 2012, 2012.

Tikhonov, A.: On the solution of incorrectly stated problems and method of regularization, Dokl. Akad. Nauk SSSR, 151, 501504, 1963.

von Clarmann, T. and Echle, G.: Selection of optimized microwindows for atmospheric spectroscopy, Appl. Optics, 37, 76617669, 1998.

von Clarmann, T., Ceccherini, S., Doicu, A., Dudhia, A., Funke, B., Grabowski, U., Hilgers, S., Jay, V., Linden, A., López-Puertas, M., Martin-Torres, F.-J., Payne, V., Reburn, J., Ridolfi, M., Schreier, F., Schwarz, G., Siddans, T., and Steck, T.: A blind test retrieval experiment for infrared limb emission spectrometry, J. Geophys. Res., 108, 4746, doi:10.1029/2003JD003835, 2003a.

von Clarmann, T., Glatthor, N., Grabowski, U., Höpfner, M., Kellmann, S., Kiefer, M., Linden, A., Mengistu Tsidu, G., Milz, M., Steck, T., Stiller, G. P., Wang, D. Y., Fischer, H., Funke, B., Gil-López, S., and López-Puertas, M.: Retrieval of temperature and tangent altitude pointing from limb emission spectra recorded from space by the Michelson Interferometer for Passive Atmospheric Sounding (MIPAS), J. Geophys. Res., 108, 4736, doi:10.1029/2003JD003602, 2003b.

von Clarmann, T., Glatthor, N., Grabowski, U., Höpfner, M., Kellmann, S., Linden, A., Mengistu Tsidu, G., Milz, M., Steck, T., Stiller, G. P., Fischer, H., and Funke, B.: Global stratospheric $\mathrm{HOCl}$ distributions retrieved from infrared limb emission spectra recorded by the Michelson Interferometer for Passive Atmospheric Sounding (MIPAS), J. Geophys. Res.,111, D05311, doi:10.1029/2005JD005939, 2006. von Clarmann, T., De Clercq, C., Ridolfi, M., Höpfner, M., and Lambert, J.-C.: The horizontal resolution of MIPAS, Atmos. Meas. Tech., 2, 47-54, doi:10.5194/amt-2-47-2009, 2009a.

von Clarmann, T., Höpfner, M., Kellmann, S., Linden, A., Chauhan, S., Funke, B., Grabowski, U., Glatthor, N., Kiefer, M., Schieferdecker, T., Stiller, G. P., and Versick, S.: Retrieval of temperature, $\mathrm{H}_{2} \mathrm{O}, \mathrm{O}_{3}, \mathrm{HNO}_{3}, \mathrm{CH}_{4}, \mathrm{~N}_{2} \mathrm{O}, \mathrm{ClONO}_{2}$ and $\mathrm{ClO}$ from MIPAS reduced resolution nominal mode limb emission measurements, Atmos. Meas. Tech., 2, 159-175, doi:10.5194/amt-2-159-2009, 2009b.

Wang, D. Y., Höpfner, M., Blom, C. E., Ward, W. E., Fischer, H., Blumenstock, T., Hase, F., Keim, C., Liu, G. Y., Mikuteit, S., Oelhaf, H., Wetzel, G., Cortesi, U., Mencaraglia, F., Bianchini, G., Redaelli, G., Pirre, M., Catoire, V., Huret, N., Vigouroux, C., De Mazière, M., Mahieu, E., Demoulin, P., Wood, S., Smale, D., Jones, N., Nakajima, H., Sugita, T., Urban, J., Murtagh, D., Boone, C. D., Bernath, P. F., Walker, K. A., Kuttippurath, J., Kleinböhl, A., Toon, G., and Piccolo, C.: Validation of MIPAS $\mathrm{HNO}_{3}$ operational data, Atmos. Chem. Phys., 7, 4905-4934, doi:10.5194/acp-7-4905-2007, 2007.

Wetzel, G., Bracher, A., Funke, B., Goutail, F., Hendrick, F., Lambert, J.-C., Mikuteit, S., Piccolo, C., Pirre, M., Bazureau, A., Belotti, C., Blumenstock, T., De Mazière, M., Fischer, H., Huret, N., Ionov, D., López-Puertas, M., Maucher, G., Oelhaf, H., Pommereau, J.-P., Ruhnke, R., Sinnhuber, M., Stiller, G., Van Roozendael, M., and Zhang, G.: Validation of MIPASENVISAT $\mathrm{NO}_{2}$ operational data, Atmos. Chem. Phys., 7, 32613284, doi:10.5194/acp-7-3261-2007, 2007.

Wetzel, G., Oelhaf, H., Berthet, G., Bracher, A., Cornacchia, C., Feist, D. G., Fischer, H., Fix, A., Iarlori, M., Kleinert, A., Lengel, A., Milz, M., Mona, L., Müuller, S. C., Ovarlez, J., Pappalardo, G., Piccolo, C., Raspollini, P., Renard, J.-B., Rizi, V., Rohs, S., Schiller, C., Stiller, G., Weber, M., and Zhang, G.: Validation of MIPAS-ENVISAT $\mathrm{H}_{2} \mathrm{O}$ operational data collected between July 2002 and March 2004, Atmos. Chem. Phys., 13, 5791-5811, doi:10.5194/acp-13-5791-2013, 2013. 